\title{
Multiple Phytohormone Signals Control the Transcriptional Response to Soybean Aphid Infestation in Susceptible and Resistant Soybean Plants
}

\author{
Matthew E. Studham ${ }^{1}$ and Gustavo C. Maclntosh ${ }^{1,2}$ \\ ${ }^{1}$ Bioinformatics and Computational Biology Program, and ${ }^{2}$ Department of Biochemistry, Biophysics, and Molecular Biology; \\ lowa State University, Ames 50011, U.S.A.
}

Submitted 21 May 2012. Accepted 7 September 2012.

\begin{abstract}
The soybean aphid (Aphis glycines) is a major phloemfeeding pest of soybean (Glycine max). A. glycines feeding can cause the diversion of photosynthates and transmission of plant viruses, resulting in significant yield losses. In this study, we used oligonucleotide microarrays to characterize the long-term transcriptional response to soybean aphid colonization of two related soybean cultivars, one with the $\operatorname{Rag} 1$ aphid-resistance gene and one aphid-susceptible cultivar (without $\operatorname{Rag} 1$ ). Transcriptome profiles were determined after 1 and 7 days of aphid infestation. Our results revealed a susceptible response involving hundreds of transcripts, whereas only one transcript changed in the resistant response to aphids. This nonexistent resistance response might be explained by the fact that many defense-related transcripts are constitutively expressed in resistant plants, whereas these same genes are activated in susceptible plants only during aphid infestation. Analysis of phytohormone-related transcripts in the susceptible response showed different hormone profiles for the two time points, and suggest that aphids are able to suppress hormone signals in susceptible plants. A significant activation of abscissic acid, normally associated with abiotic stress responses, at day 7, might be a decoy strategy implemented by the aphid to suppress effective salicylic acid- and jasmonate-related defenses.
\end{abstract}

The soybean aphid (Aphis glycines Matsumura) is a phloemfeeding pest native to Asia that was first spotted in North America in 2000, and it has since spread to all the main soybean (Glycine max)-producing states in the United States (Ragsdale et al. 2011). During the summer, aphids reproduce rapidly by parthenogenesis, living and feeding on soybean plants. Soybean aphid populations can double in less than 2 days, and a single soybean plant can be infested with thousands of aphids (McCornack et al. 2004). There are three known soybean aphid biotypes: biotype 1 or Illinois isolate, biotype 2 or Ohio isolate, and biotype 3 . These biotypes differ in their ability to colonize plants carrying the Ragl and Rag2 soybean resistance $(R)$ genes (Hill et al. 2010; Kim et al. 2008).

Corresponding author: G. C. MacIntosh; E-mail: gustavo@iastate.edu

* The $\boldsymbol{e}$-Xtra logo stands for "electronic extra" and indicates that two supplementary figures, two supplementary tables, and a gene set analysis data file are published online.

(C) 2013 The American Phytopathological Society
Aphids feed by inserting their stylets into the plant's vascular tissue, specifically the sieve elements, where they obtain phloem sap (Will and van Bel 2006). This type of feeding causes minimal damage to the plant compared with chewing insects. However, the resulting diversion of photosynthates can lead to yield losses of up to $40 \%$ in soybean (Ragsdale et al. 2011), with lower number of pods per plant, lower number of seeds per pod, smaller seeds, and lower oil content of the seed (Beckendorf et al. 2008). Aphids cause further harm by spreading soybean viruses such as the Soybean mosaic virus (Hill et al. 2001).

It has been hypothesized that plants recognize aphid attack by detecting elicitors, possibly aphid salivary proteins (De Vos and Jander 2009; Lapitan et al. 2007; Ma et al. 2010) or the insect exoskeleton oligosaccharide chitin (Libault et al. 2007). Studies of different plant-aphid interactions have shown that plant responses to aphid attack involve one or more of the following hormones: salicylic acid (SA), jasmonic acid (JA), and ethylene (ET). SA is regarded as the most common hormonal response to biotrophs (Loake and Grant 2007), and its participation in responses to aphid colonization has been documented in barley (Chaman et al. 2003), Arabidopsis (Mewis et al. 2005), tomato ( $\mathrm{Li}$ et al. 2006), and soybean ( $\mathrm{Li}$ et al. 2008). JA plays a dominant role in plant defenses against chewing insects (Howe and Jander 2008) but there is evidence that it is also involved in the response to aphids in Arabidopsis (De Vos et al. 2007; Ellis et al. 2002) and Medicago truncatula (Gao et al. 2007). Experiments in cucumber (Walz et al. 2004), barley (Gutsche et al. 2009), and celery (Divol et al. 2005) indicate that ET responses are induced by aphid infestation. In addition, the participation of abscissic acid (ABA) has been proposed in the response to aphid infestation in barley (Casaretto et al. 2004), eggplant, and squash (El-Khawas and El-Khawas 2008). ABA has an essential role in abiotic stress tolerance; although its role in plant-aphid interactions is not clear, it has been shown to participate in pathogen resistance (Asselbergh et al. 2008).

The balance of phytohormones leads to the expression of response genes and, eventually, a specific biochemical defense. Unfortunately, with the exception of the well-characterized role of specific glucosinolates as deterrents of Myzus persicae colonization in Arabidopsis (De Vos et al. 2007), little is known about these specific defenses against aphids. In soybean, it has been proposed that the emission of methyl salicylate (methyl-SA), a volatile derivative of SA, can function as an indirect defense, because this volatile can attract lady beetles (Coccinella septempunctata), which are major predators of soybean aphids (Zhu and Park 2005). Furthermore, methyl-SA 
emission has been shown to be part of an aphid response in alfalfa, silver birch, and black alder, suggesting that methylSA can have a similar role in other plant species (Blande et al. 2010; Pareja et al. 2009).

It has been proposed that aphids can counter plant defenses by suppressing the defense response through the activation of an antagonistic decoy response (Walling 2008). One example of possible suppression by a phloem feeder is found in tomato. Potato aphids induce ET-associated transcripts and an intact ET pathway is required for virulence, whereas ET does not appear to be necessary for aphid resistance (Mantelin et al. 2009). In this case, the induction of ET can be considered a decoy response that may antagonize the induction of a biologically effective defense. Silverleaf whiteflies, also phloem-feeding insects, may suppress an effective JA defense by inducing an SA-dependent defense response in Arabidopsis (Zarate et al. 2007). In both examples, the phloem-feeders appear to be manipulating the crosstalk among different defense pathways to suppress the effective defense.

Aphid-resistant cultivars have been identified in several plant species; however, the Mi-1.2 gene of tomato (Solanum lycopersicum) is the only cloned aphid-resistance gene that has been well characterized. $\mathrm{Mi}-1.2$ encodes a protein with a coiled-coil nucleotide-bind site leucine-rich repeat motif, functions as a single dominant gene, and confers resistance to a biotype of the potato aphid (Macrosiphum euphorbiae), as well as to the rootknot nematode (Meloidogyne spp.) and sweet potato whitefly (Bemisia tabaci) (Kaloshian et al. 1995; Milligan et al. 1998; Nombela et al. 2003; Rossi et al. 1998). Mi-1.2 aphid resistance involves SA signaling, and SA-induced pathogenesis-related $(P R)-1$ transcript levels increase in response to aphid infestation in plants carrying this $R$ gene ( $\mathrm{Li}$ et al. 2006). Local expression of $M i-1.2$ is required for aphid resistance (Martinez de Ilarduya et al. 2003) but increased $M i-1.2$ transcript levels do not result in increased resistance (Goggin et al. 2004).

Several soybean cultivars are resistant to soybean aphids, including 'Dowling', 'Jackson', 'Sugao Zairai', and 'Cobb'. At least three single dominant aphid-resistance genes have been found in soybean: Rag1, Rag2, Rag3, and an unnamed gene in Jackson. Ragl controls the Illinois isolate of the soybean aphid (Kim et al. 2008) and is found in Dowling (Hill et al. 2006a). Ragl significantly reduces aphid life expectancy and reproductive rate and increases nymph mortality (Li et al. 2004). Electrical penetration graph studies showed that soybean aphids find it more difficult to establish and maintain phloem feeding on Dowling plants as opposed to an aphid-susceptible variety, leading to the hypothesis that Ragl resistance is expressed in the sieve element (Crompton and Ode 2010; Diaz-Montano et al. 2007). Unlike tomato $M i-1.2$, Ragl does not confer resistance to root-knot nematodes nor does it confer resistance to soybean cyst nematodes (Studham et al. 2009). Rag2 is found in plant introduction (PI) 243540 and is probably responsible for resistance in Sugao Zairai (Hill et al. 2009; Mian et al. 2008). Rag 2 confers strong antibiosis-type resistance to soybean aphid biotypes 1 and 2 (Kang et al. 2008). Rag3 controls several aphid biotypes, including biotype 2, and is thought to confer antixenotic resistance (Zhang et al. 2010). Finally, the $R$ gene in Jackson is responsible for antibiotic and possible antixenotic resistance (Hesler and Dashiell 2007; Hill et al. 2006b). In addition to these single dominant genes that could fit in the category of classical $R$ genes, two soybean lines (PI $567541 \mathrm{~B}$ and PI 567598B) were reported to have strong antibiosis resistance due to at least two recessive genes (Mensah et al. 2005, 2008), possibly indicating the existence of important susceptibility $(S)$ genes in soybean.

In the first large-scale transcriptional profiling of the soybean response to aphids, Li and associates (2008) used cDNA microarrays, representing over 18,000 soybean genes, to reveal significant responses in both aphid-susceptible ('Williams 82') and aphid-resistant (Dowling) plants after 6 and $12 \mathrm{~h}$ of aphid infestation. They observed a significant resistance response that was stronger at $6 \mathrm{~h}$ post-application (hpa) than at $12 \mathrm{hpa}$. This response induced many defense-related genes, including homologs of $R$ genes, PR proteins (PR1a, P21, and P-5), hypersensitive-response-associated proteins, and antimicrobial proteins. Other genes induced in the resistance response were transcription factors (including WRKY factors), genes associated with the phenylpropanoid pathway, and a JA biosynthesis gene. Most of the 140 transcripts involved in the resistance response overlapped with the incompatible response to Pseudomonas syringae. The susceptible response to aphids was smaller and slower than the resistance response and only a few genes were common to both. Surprisingly, when the transcript profiles of $\mathrm{R}$ plants and S plants without aphids were compared, only five genes showed higher expression levels in $\mathrm{R}$ plants over all the time points, even though the two lines are genetically unrelated.

Previous analyses of the soybean response to Asian soybean rust showed that it is biphasic, with a strong early response in both $\mathrm{S}$ and $\mathrm{R}$ plants, followed by a differential response (rapid for $\mathrm{R}$, slower for $\mathrm{S}$ ) in the late phase of infection (van de Mortel et al. 2007). In this work, we aimed at complementing the analysis of the early response to the soybean aphid to investigate whether the response to this pest is also biphasic. Our experiment used Affymetrix GeneChip Soybean oligonucleotide arrays, representing an estimated 22,763 soybean genes, to determine a later response ( 24 and $168 \mathrm{hpa}$ ) to aphids in two closely related soybean lines, one aphid susceptible and one carrying the Ragl gene and, thus, aphid resistant. We found that, during this late interaction, only $\mathrm{S}$ plants show a strong transcriptional response. We also found differences between uninfested $\mathrm{R}$ and $\mathrm{S}$ plants, which could be interpreted as signs of constitutive resistance or differential response to priming. Finally, we used pathway analysis to determine the participation of common phytohormone pathways in the response to aphid colonization, and further characterized the role of ET and SA in this interaction.

\section{RESULTS}

\section{Transcriptional response to soybean aphid infestation.}

To assess soybean transcriptional response to aphids, a nochoice growth chamber experiment was conducted using two related lines: aphid-resistant LD16060 (R plants) with the Ragl gene and aphid-susceptible SD01-76R (S plants). At the V3 growth stage, one-half of the plants for each line were infested with soybean aphids. Profiling of leaf mRNA was carried out after 1 and 7 days of infestation. Aphids were counted on the plants at the time of leaf sampling. The aphid population levels on R plants were significantly lower than the levels on S plants (Supplementary Fig. S1B), even after only $24 \mathrm{~h}$, confirming $\mathrm{R}$ line resistance. Aphid populations increased on $\mathrm{R}$ plants but at a much slower pace than on $\mathrm{S}$ plants.

Gene expression was determined using Affymetrix GeneChip Soybean Genome Array, which contains $>37,600$ soybean probe sets that correspond to an estimated 22,763 soybean genes (approximately $49 \%$ of the genome) (Schmutz et al. 2010) according to the Soybase website. At each time point, we compared the susceptible response (S plants, infested versus noninfested), the resistance response ( $\mathrm{R}$ plants, infested versus noninfested), and genetic differences (noninfested $\mathrm{R}$ plants versus noninfested $\mathrm{S}$ plants). We used very stringent parameters to analyze our results. Genes were considered to be differentially expressed (DE) if their corresponding transcript levels showed a statistically significant $(P \leq 0.0001)$ change of 
at least twofold and, overall, there was a false discovery rate (FDR) lower than 4\% $(q \leq 0.04)$ (Storey et al. 2004). The number of DE genes for each comparison and time point is shown in Figure 1. With these criteria, there were 677 unique DE genes for the three comparisons and two time points. There was a significant susceptible response to aphids, and it increased with the duration of infestation. However, the resistance response was limited to a unique gene encoding for a hypothetical protein at 7 days postinoculation. Thus, $\mathrm{R}$ plants dramatically decelerated aphid population growth without a strong measurable transcriptional response at the times analyzed here. There were also significant genetic differences for plants without aphids.

The clustering heat map (Fig. 2) illustrates different response profiles. The aphid effect and genetic effect components of the statistical model for both time points were used to group DE transcripts. The vast majority of DE genes were upregulated by aphid infestation or present at higher levels in R plants, and many of the genes involved in the susceptible response also appeared in the genetic differences. $S$ response genes induced on day 1 either were also upregulated in uninfested $\mathrm{R}$ plants (compared with $\mathrm{S}$ control) or the genes remained induced on day 7 . There was no significant early (day 1) unique susceptible response, and only a few genes were repressed at this stage. There were more DE genes on day 7 than day 1, indicating that the susceptible response had not peaked after 1 day of infestation.

\section{Susceptible response.}

$\mathrm{S}$ plants responded to aphid infestation by inducing genes involved in many different biological processes, including defense response, ABA response, ET signaling and biosynthesis, amino acid transport, cell wall modification, and lipid metabolism, among others. Supplementary Table S1 lists a subset of the DE transcripts involved in the susceptible response. After 1 day of infestation, 49 genes significantly changed: 46 were induced and 3 were suppressed. The response was greater after 7 days of infestation: 280 genes were induced and 4 were suppressed.

Among the DE genes, 38 correspond to transcription factors (Table 1). Eight of these transcripts are upregulated in the day 1 and day 7 responses, while the rest are only differentially upregulated in the later response. Two families of transcription factors (AP2 domain and zinc finger/C2H2) are highly represented in the DE set and are associated with abiotic stress

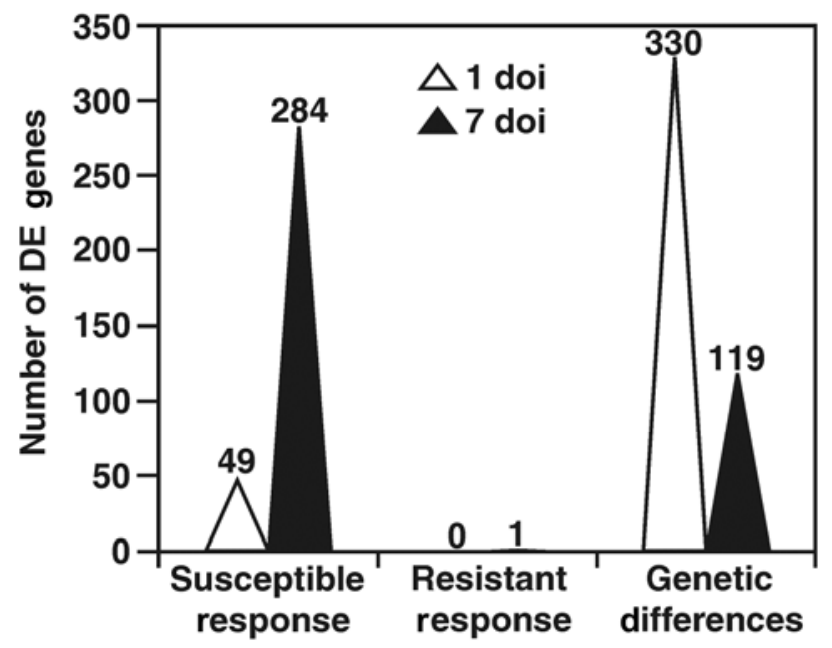

Fig. 1. Responses to aphid infestation and genetic differences. Numbers of differentially expressed (DE) soybean genes for three different comparisons for both time points: 1 day of infestation ( 1 doi) and 7 days of infestation (7 doi). responses, mainly cold stress and water stress. SCOF-1 (Glyma17g35430), a zinc-finger transcription factor, has been well characterized as a regulator of the ABA response (Kim et al. 2001). SCOF-1 can interact with ABRE transcriptions factors, some of which are also DE in our dataset. Several AP2 domain transcription factors have also been associated with ET response.

The other DE transcripts belong to families of transcription factors that have been implicated in plant defense, including the NAC (NAM, ATAF1,2, and CUC2), CCR4-NOT complex

\section{Aphids-1 Genetic-1 Aphids-7 Genetic-7}

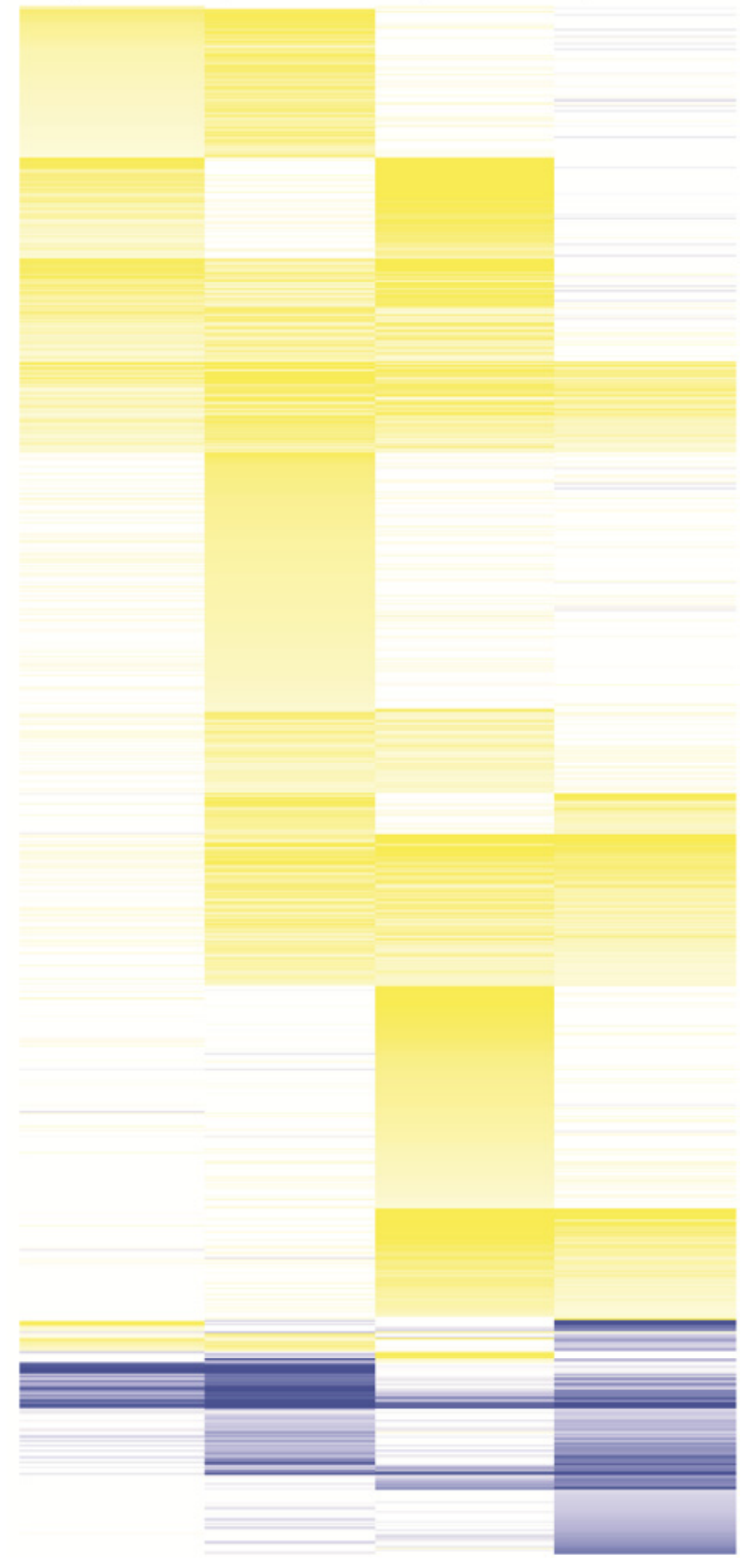

Fig. 2. Heat map showing clusters of genes involved in the susceptible response to aphids and genetic differences between the resistant and susceptible lines. K-medoid clustering was used to group genes according to their aphid response and genetic difference components from the statistical model for each time point. Each column represents a model component and each row is a probe set. A three-color scale illustrates the values for each probe set and component: yellow for upregulation, white for no change, and blue for downregulation. Genes included in these clusters are differentially expressed for at least one comparison. There is a total of 944 probe sets. 
and WRKY families. WRKY factors are central components of many aspects of the innate immune system of the plant (Rushton et al. 2010). Interestingly, Glyma19g40560 and its Arabidopsis homolog (WRKY23) are upregulated during the establishment of feeding sites the by cyst nematodes Heterodera glycines and $H$. schachtii in soybean and Arabidopsis, respectively (Grunewald et al. 2008). CCR4-associated factor 1 (CAF1) proteins (Glymal1g18460 and Glyma12g09830) belong to the CCR4-NOT complex, an evolutionary conserved protein complex that plays an important role in the control of transcription and mRNA decay (Belostotsky and Sieburth 2009; Liu et al. 2001). Overexpression of a CAF1 gene from pepper in tomato resulted in resistance to the oomycete pathogen Phytophthora infestans; conversely, silencing pepper
CAF1 produced plants with increased susceptibility to the pathogen Xanthomonas axonopodis pv. vesicatoria (Sarowar et al. 2007). Glyma02g12220 and Glyma02g38710 are members of the NAC transcription factor family; this class of transcription factors has also been implicated in defense responses and may be a node of crosstalk between JA and ABA signaling $(\mathrm{Bu}$ et al. 2008; Jiang et al. 2009; Olsen et al. 2005).

A gene set analysis, using the GSA method (Efron and Tibshirani 2007) with GO biological processes (Ashburner et al. 2000) as sets and a 5\% FDR, revealed additional aspects of the susceptible response (Supplementary Data File S1). Induced DE gene sets for day 1 included many defense and immune response processes, as well as bacterium response. There was also a strong induction of JA signaling, biosynthesis, and me-

Table 1. Transcription factor genes differentially expressed in susceptible plants in response to soybean aphid infestation ${ }^{\mathrm{a}}$

\begin{tabular}{|c|c|c|c|c|c|}
\hline Probe $^{b}$ & Gene ID $^{c}$ & Family & Annotation or comment ${ }^{d}$ & $\mathbf{Q}$ & Fold change \\
\hline \multicolumn{6}{|l|}{ Day $1 \mathrm{SA}$ versus SC } \\
\hline GmaAffx.84921.1.S1_at & Glyma09g08330 & AP2 domain & AP2/ERF domain- transcription factor & $3.40 \mathrm{E}-02$ & 8.74 \\
\hline Gma.6009.1.S1_s_at & Glyma06g44430 & AP2 domain & AP2/ERF domain- transcription factor & $3.40 \mathrm{E}-02$ & 3.30 \\
\hline GmaAffx.7874.2. $\bar{S} 1$ 1_s_at & Glyma10g23440 & AP2 domain & AP2/ERF domain- transcription factor & $3.40 \mathrm{E}-02$ & 2.39 \\
\hline Gma.15724.1.S1_at & Glyma11g18460 & CCR4-NOT & CAF1 family ribonuclease & $3.40 \mathrm{E}-02$ & 3.92 \\
\hline Gma.15724.1.S1_a_at & Glyma12g09830 & CCR4-NOT & CAF1 family ribonuclease & $3.86 \mathrm{E}-02$ & 2.98 \\
\hline Gma.17736.1.S1_at & Glyma03g33070 & Zinc finger, $\mathrm{C} 2 \mathrm{H} 2$ & $\ldots$ & $3.40 \mathrm{E}-02$ & 9.95 \\
\hline Gma.235.1.S1_x_at & Glyma17g35430 & Zinc finger, $\mathrm{C} 2 \mathrm{H} 2$ & SCOF-1 & $3.40 \mathrm{E}-02$ & 4.61 \\
\hline Gma.986.1.S1_at & Glyma15g04570 & Zinc finger, $\mathrm{C} 2 \mathrm{H} 2$ & $\ldots$ & $3.40 \mathrm{E}-02$ & 4.38 \\
\hline \multicolumn{6}{|l|}{ Day $7 \mathrm{SA}$ versus SC } \\
\hline GmaAffx.84921.1.S1_at & Glyma09g08330 & AP2 domain & $\begin{array}{l}\text { Similar to GmDREB3 (cold induced, ABA } \\
\text { independent) }\end{array}$ & $6.5 \mathrm{E}-06$ & 34.2 \\
\hline GmaAffx.2501.2.S1_at & Ambiguous Hit & AP2 domain & CBF-like protein $\mathrm{ABA}$ /abiotic & $2.4 \mathrm{E}-03$ & 18.9 \\
\hline GmaAffx.78315.1.S1_at & Glyma $17 \mathrm{~g} 05240$ & AP2 domain & GmDREB3 (cold induced, ABA independent) & $6.9 \mathrm{E}-05$ & 13.0 \\
\hline Gma.17470.1.S1_x_at & Glyma12g13320 & AP2 domain & ET-responsive transcription factor & $1.5 \mathrm{E}-03$ & 7.37 \\
\hline Gma.6009.1.S1_s_at & Glyma06g44430 & AP2 domain & ET-responsive transcription factor & $9.6 \mathrm{E}-05$ & 6.56 \\
\hline Gma.6426.1.S1_at & Glyma12g35550 & AP2 domain & ET-responsive transcription factor & 4.3E-03 & 6.02 \\
\hline Gma.5293.2.S1_at & Glyma17g15460 & AP2 domain & ET-responsive transcription factor & $1.1 \mathrm{E}-04$ & 4.51 \\
\hline GmaAffx.7874.2.S1_at & Glyma10g23440 & AP2 domain & ET-responsive transcription factor & $2.6 \mathrm{E}-04$ & 4.31 \\
\hline Gma.9553.1.A1_at & Glyma14g06080 & AP2 domain & dehydration responsive element & 3.3E-03 & 4.21 \\
\hline Gma.8372.2.S1_at & Glyma06g04490 & AP2 domain & $\begin{array}{l}\text { Drought responsive element binding protein 2- } \\
\text { DREB2 }\end{array}$ & $4.2 \mathrm{E}-03$ & 4.11 \\
\hline Gma.8372.1.S1_a_at & Glyma04g04350 & AP2 domain & Drought responsive element binding protein & $1.8 \mathrm{E}-03$ & 3.63 \\
\hline Gma.1124.1.S1_at & Glyma02g46340 & AP2 domain & ET-responsive transcription factor & $1.4 \mathrm{E}-03$ & 3.62 \\
\hline Gma.15943.1.S1_at & Glyma11g03900 & AP2 domain & ET-responsive transcription factor & $2.8 \mathrm{E}-03$ & 3.45 \\
\hline Gma.16700.1.S1_at & Glyma20g16920 & AP2 domain & ET-responsive transcription factor & 4.3E-03 & 3.43 \\
\hline GmaAffx.7874.1.S1_s_at & Glyma20g16910 & AP2 domain & ET-responsive transcription factor & $5.0 \mathrm{E}-04$ & 3.29 \\
\hline Gma.16611.1.S1_at & Glyma04g11290 & AP2 domain & Dehydration responsive element-binding protein 3 & $2.5 \mathrm{E}-03$ & 2.25 \\
\hline GmaAffx.89624.1.A1_s_at & Ambiguous Hit & bZIP & ABRE & $1.8 \mathrm{E}-03$ & 4.64 \\
\hline GmaAffx.89944.1.S1_s_at & Glyma17g37510 & bZIP & ABRE & $2.5 \mathrm{E}-03$ & 2.91 \\
\hline Gma.15724.1.S1_at & Glyma11g18460 & CCR4-NOT & CAF1 family ribonuclease & $6.9 \mathrm{E}-05$ & 8.36 \\
\hline Gma.15724.2.S1_at & Glyma12g09830 & CCR4-NOT & CAF1 family ribonuclease & 5.9E-04 & 5.82 \\
\hline GmaAffx.42667.3.S1_at & Glyma14g27290 & GRAS family & scarecrow-like protein 1 -like & $2.5 \mathrm{E}-03$ & 2.34 \\
\hline GmaAffx.1785.1.S1_at & Glyma16g02390 & Homeobox & $\begin{array}{l}\text { Homeobox-leucine zipper protein ATHB-7 (water } \\
\text { deficit and ABA) }\end{array}$ & $3.0 \mathrm{E}-03$ & 16.7 \\
\hline Gma.16603.1.S1_at & Glyma16g32070 & HSF & $\begin{array}{l}\text { Heat-shock TF family (heat stress transcription } \\
\text { factor B-2a- response to chitin) }\end{array}$ & $2.8 \mathrm{E}-03$ & 2.34 \\
\hline Gma.17786.1.S1_at & No match & NAM/NAC & $\ldots$ & $1.0 \mathrm{E}-03$ & 5.30 \\
\hline Gma.1748.1.S1_at & Glyma02g12220 & NAM/NAC & NAC1 protein & $1.7 \mathrm{E}-03$ & 5.25 \\
\hline Gma.4774.2.S1_at & No match & NAM/NAC & $\ldots$ & $2.1 \mathrm{E}-03$ & 3.17 \\
\hline Gma.7991.1.S1_at & Glyma02g38710 & NAM/NAC & $\ldots$ & $1.8 \mathrm{E}-03$ & 2.49 \\
\hline Gma.8336.1.S1_at & Glyma19g40560 & WRKY & WRKY23 (Arabidopsis) & $4.2 \mathrm{E}-03$ & 3.66 \\
\hline GmaAffx.86530.1.S1_at & Glyma03g37940 & WRKY & WRKY23 (Arabidopsis) & 4.7E-03 & 2.47 \\
\hline Gma.15748.1.A1_at & Glyma02g15920 & WRKY & WRKY21 (Arabidopsis) & 2.3E-03 & 2.38 \\
\hline Gma.17736.1.S1_at & Glyma03g33070 & Zinc finger, $\mathrm{C} 2 \mathrm{H} 2$ & $\ldots$ & $6.5 \mathrm{E}-06$ & 29.1 \\
\hline Gma.986.1.S1_at & Glyma15g04570 & Zinc finger, $\mathrm{C} 2 \mathrm{H} 2$ & $\ldots$ & $8.0 \mathrm{E}-06$ & 12.6 \\
\hline Gma.235.1.S1_at & Glyma17g35430 & Zinc finger, $\mathrm{C} 2 \mathrm{H} 2$ & SCOF-1 & $5.8 \mathrm{E}-05$ & 10.2 \\
\hline Gma.235.2.S1_a_at & Glyma14g09760 & Zinc finger, $\mathrm{C} 2 \mathrm{H} 2$ & Most similar to SCOF-1 & $5.2 \mathrm{E}-05$ & 9.66 \\
\hline GmaAffx.92932.1.S1_s_at & Glyma04g04760 & Zinc finger, $\mathrm{C} 2 \mathrm{H} 2$ & Similar to SCOF-1 & $5.0 \mathrm{E}-05$ & 8.71 \\
\hline Gma.4472.1.S1_at & Glyma20g26940 & Zinc finger, $\mathrm{C} 2 \mathrm{H} 2$ & Similar to SCOF-1 & $2.1 \mathrm{E}-03$ & 7.49 \\
\hline Gma.4526.1.S1_at & Glyma10g05210 & Zinc finger, $\mathrm{C} 2 \mathrm{H} 2$ & $\ldots$ & $1.8 \mathrm{E}-03$ & 5.93 \\
\hline Gma.16613.1.S1_at & Glyma10g40400 & Zinc finger, $\mathrm{C} 2 \mathrm{H} 2$ & Similar to SCOF-1 & $1.1 \mathrm{E}-03$ & 4.94 \\
\hline
\end{tabular}

${ }^{a}$ Gene ID was assigned using SoyBase. For probes with no match to a gene model or with ambiguous matches, Affymetrix annotation was used.

${ }^{\mathrm{b}} \mathrm{SA}=$ susceptible plant with aphids and $\mathrm{SC}=$ susceptible plant without aphids.

${ }^{\mathrm{c}}$ No match $=$ no match to a soybean gene model.

${ }^{\mathrm{d}} \mathrm{ABA}=$ abscissic acid and $\mathrm{ET}=$ ethylene. 
tabolism processes. For day 7, gene sets related to abiotic stress (response to cold and response to water deprivation) and ABA biosynthesis, metabolism, and signaling were induced, whereas the JA and defense-related gene sets were no longer induced. The individual gene and gene set analyses suggested that the phytohormones ABA, ET, and JA are involved in the compatible response to aphids.

Quantitative real-time polymerase chain reaction (qPCR) was used to confirm the microarray results. The changes in gene expression at day 7 for four genes (SCOF-1, 1-aminocyclopropane-1-carboxylic acid [ACC] synthase, an amino acid transporter, and a gene-silencing regulator) measured by qPCR agreed with microarray results (Fig. 3A), although the qPCR fold changes were consistently higher. For this analysis, we also included an independent experiment different from the three replicates used in microarray analysis. In this experiment, the aphid population increased at a slower rate than the normal growth observed in our microarray experiments (Fig. $3 B)$. The fold changes in gene expression observed for the extra experiment are lower than the fold changes in the original experiment for all four genes analyzed, although all showed significant upregulation as observed in the microarray experiments. Although the reason for the slower aphid population growth observed in the last experiment is unclear, there seems to be a correlation between aphid number and gene expression.

\section{Resistance response.}

The only transcript that responded to aphid infestation in the $\mathrm{R}$ plants corresponded to a small hypothetical protein of 83 amino acids (probe Gma.4430.1.S1_at, corresponding to gene model Glyma06g14090) that was induced after 7 days of infestation. However, a gene set analysis determined that there were many DE gene sets, even though the individual genes were not DE. This observation highlights the advantage of using gene sets as opposed to individual gene analysis: the signal-to-noise ratio is effectively increased and modest changes become statistically significant. Among day 1 DE gene sets, we found upregulation of cell wall metabolism, cuticle development, response to nematode, regulation of programmed cell death, and lipid metabolism and downregulation of response to insect, auxin metabolism, gibberellic acid signaling, and nucleic acid metabolism. For day 7, ET signaling, ET response, and lipid biosynthesis were induced and JA biosynthesis, JA metabolism, and cell plate formation were suppressed.

\section{Genetic differences.}

The two related soybean cultivars (LD05-16060 and SD0176R) used in our experiment have transcriptional differences in the absence of aphid infestation. A subset of the DE transcripts and their fold changes for both time points is listed in Supplementary Table S2. Aphid-resistant plants (without aphids) showed differences in the transcript levels of 424 unique genes for one or both time points when compared with aphid-susceptible plants (without aphids). In terms of number of transcripts, the genetic differences were larger than the susceptible response. Reverse-transcribed (RT)-PCR confirmed the changes in several individual transcripts (Supplementary Fig. S2). A gene set analysis indicated that transcripts related to ABA signaling and response, insect response, xenobiotic response, transport regulation, and viral response were among those elevated in the aphid-resistant control plants for one or both time points. The same analysis indicated that several gene sets were suppressed, including those involved in nematode response, cell wall metabolism, lipid metabolism and transport, hormone transport, and nitric oxide metabolism.

Because the two lines used in this study are not near-isogenic, the difference in gene expression between them in the absence of aphids is not surprising. However, many of the genes DE in R plants seem to be important for defense against aphids. The Venn diagram in Figure 4 illustrates that many of the genes included in the genetic differences are also involved in the susceptible response. For day 1 (Fig. 4A), 35\% of the genes induced in the susceptible response are already at higher levels in aphid-resistant plants without aphids; for day 7 (Fig. $4 \mathrm{~B}$ ), this number is approximately $8.5 \%$. These overlaps include genes related to ET biosynthesis and response, cell wall metabolism, amino acid transport, and defense-related genes.

The published soybean genome sequence was obtained from the Williams-82 variety (Schmutz et al. 2010) and, therefore, does not have the Ragl gene. However, the soybean genome does have several gene models located in the same $115-\mathrm{kbp}$ range to which Ragl was mapped (Kim et al. 2010). Our micro-
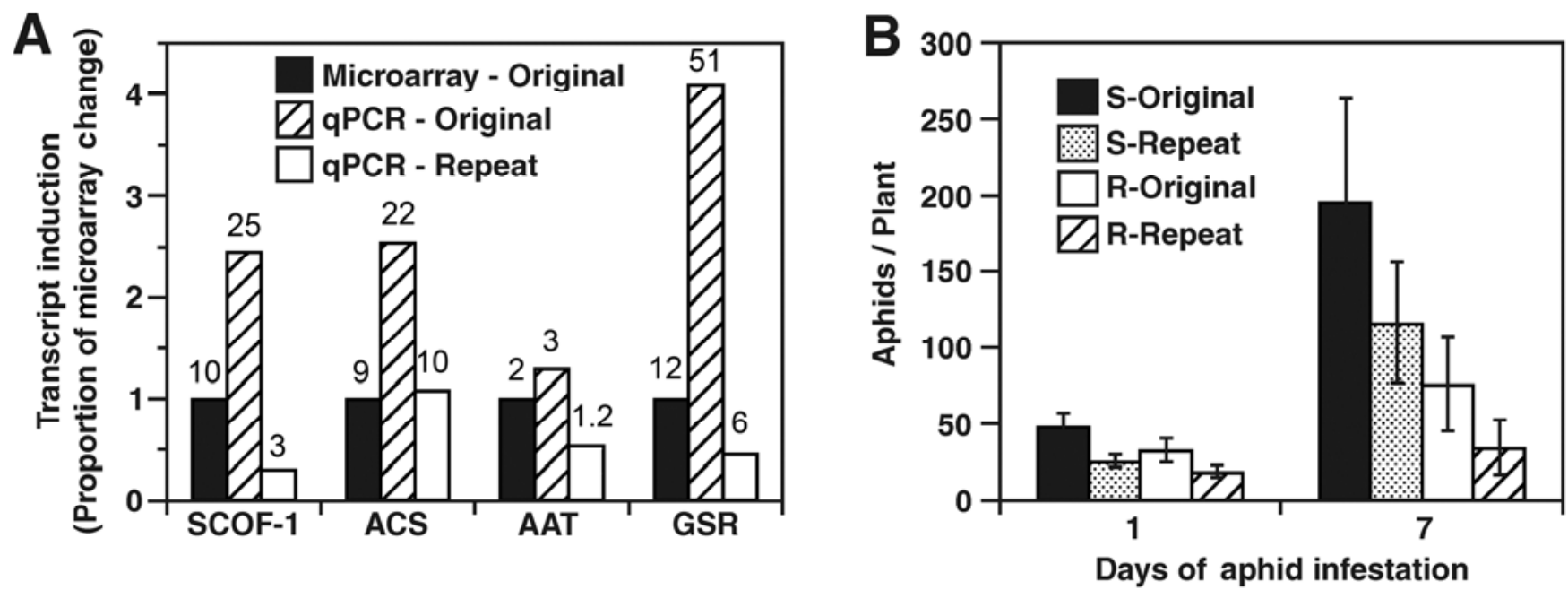

Fig. 3. A, Confirmation of microarray results using quantitative real-time reverse-transcribed polymerase chain reaction (qPCR). SCOF-1 (Gma.235.1.S1_at), ACS (ACC synthase, Gma.1332.1.S1_x_at), AAT (amino acid transporter, GmaAffx.765.1.S1_at), and GSR (gene-silencing regulator, GmaAffx.3696.1.S1_at) were induced in the susceptible response after 7 days of aphid infestation. qPCR was used to determine the fold changes for tissue samples from the original experiment (Original) and a repeat experiment (Repeat). The vertical axis scale is the fold change divided by the microarray fold change for each sample. B, Aphid population levels on susceptible and resistant plants for both time points in the original and repeat experiments. Thirty aphids were initially applied and the difference between resistant and susceptible levels was statistically significant $(t$ test, $P<0.05)$ for both time points in both experiments. The difference between the two experiments was also statistically significant for all common treatments. 
array results revealed that a transcript (GmaAffx.27712.1.S1_at) that maps to a gene in that same range (Glyma07g06940) is consistently expressed only in the $\mathrm{R}$ plants. There is no detailed annotation for this transcript but it might be co-expressed with Ragl.

\section{Comparison with the cDNA microarray experiment}

$\mathrm{Li}$ and associates (2008) used cDNA microarrays to determine the soybean's transcriptional response to aphids for very early time points (after 6 and $12 \mathrm{~h}$ of infestation) for aphidresistant (Dowling) and aphid-susceptible (Williams 82) cultivars. Their results showed a significant resistance response to aphids while our later time points (24 and $168 \mathrm{~h}$ ) showed almost no such response. Although we had different aphidresistant cultivars, the Ragl gene conferred resistance in both; therefore, the differing resistance response is probably not due to genetic differences. It is more likely that the transcriptional response in the R plant, which peaks at $6 \mathrm{~h}$, is completed $24 \mathrm{~h}$ after the beginning of aphid infestation. The cDNA microarray showed that the response to aphids overlapped with the response to Pseudomonas syringae (Li et al. 2008). Similarly, our results identified six transcripts involved in the susceptible response (Gma.8448.1.S1_at, GmaAffx.23402.1.S1_at, Gma.120.1.S1_at, Gma.8448.1.S1_at, Gma.117.1.S1_at, and Gma.8447.1.S1_at) whose annotations indicate that they are induced by syringolides, low molecular weight glycolipid elicitors produced by the protein encoded by the $P$. syringae avirulence gene D ( $a v r D)$ (Midland et al. 1993). However, no overlap was observed between DE genes in the early (6- and 12-h) and late (1- and 7-day) responses. Individual transcripts from the cDNA experiment and our Affymetrix array experiment were matched up based on the probe target sequence. Most $(70 \%)$ of the cDNA probes matched with one or more Affymetrix probes but none of the DE transcripts from Li and associates (2008) were DE in our experiment based on our stringent criteria.

\section{Effect on hormone pathways.}

We used a hormone pathway analysis tool (Studham and MacIntosh 2012) to study changes in the transcript levels of genes associated with the hormones ABA, ET, JA, and SA, and compared the involvement of these hormones in the response to aphids. To evaluate the participation of each hormone pathway, a score was calculated based on the fold changes and significance of the changes in the transcripts corresponding to each pathway for every comparison and experiment. This analysis included a larger dataset than the set of DE genes de- scribed previously; we defined a relaxed cutoff that incorporated all transcripts with absolute fold changes $\geq 1.2$ and $q$ values $\leq 0.20$, and this dataset was used to calculate the score. We used this relaxed cutoff in order to include more transcripts and increase the sensitivity of the analysis, knowing that significance and fold change are taken into account by the analysis tool (Studham and MacIntosh 2012). A total score and scores for only biosynthesis genes or individual marker genes were obtained. The individual marker genes were ATAF1 ( Lu et al. 2007) for ABA, ACC oxidase (Kim et al. 1997) for ET, JAR1 (Staswick and Tiryaki 2004) for JA, and EDS1 (Falk et al. 1999) for SA. Results of the pathway analysis are shown in Figure 5, with yellow indicating induction and blue indicating suppression. The day 1 susceptible response is relatively weak overall but SA seems to be favored over other hormone responses. Day 7 results show that the ABA pathway is strongly induced, whereas JA, ET, and SA are less prominent overall. The resistance response shows no significant changes.

More interesting observations result from the separate analysis of biosynthetic pathways and response genes for each hormone during the susceptible response to aphids. On day 1 , individual markers follow the production of each hormone as determined by the regulation of the biosynthetic genes. On day 7 , biosynthesis of ABA and expression of the corresponding marker gene are strongly induced, whereas SA biosynthesis is suppressed and the expression of the corresponding marker gene is lower than for day 1 . However, on day 7 , biosynthetic genes for ET and JA are strongly induced while the individual ET- or JA-responsive genes are not expressed. This could indicate a block in the signaling pathway leading to the induction of the response to these hormones.

The genetic differences in these pathways were significant on day 1 , and biosynthesis transcripts were at higher levels in the $\mathrm{R}$ plant for all four hormones. On day 1 , the strongest response corresponded to SA, followed by ET- and JA-related transcripts, while the ABA signal was less significant. However, on day 7, ABA was the only hormone with consistently higher levels in the R plant, while ET and SA were downregulated.

\section{Effect of ET pre-treatment on aphid performance.}

ET biosynthesis and response transcripts were DE in the susceptible response to aphids (Fig. 5), and ET signaling and response gene sets were induced in the resistance response. These results suggest that ET could have a significant role in the response to aphid infestation in soybean. To test this putative role, we performed an experiment to determine whether
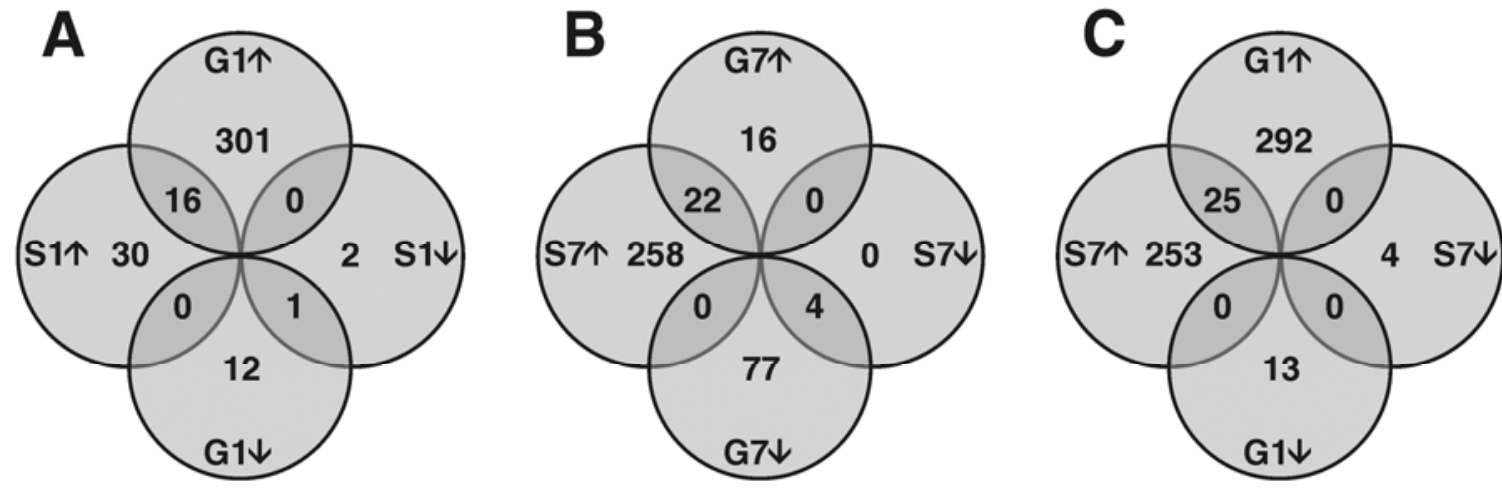

Fig. 4. Venn diagrams illustrate the overlap of the susceptible response and genetic differences. Each circle represents one comparison $(\mathrm{S}=$ susceptible response, $\mathrm{G}=$ genetic differences) and time point ( 1 and 7 days of infestation) and direction of change (up $\uparrow$ or down $\downarrow$ ). Inside each circle is the number of differentially expressed genes. A, Overlap of susceptible response and genetic differences after 1 day of infestation. B, Overlap of susceptible response and genetic differences after 7 days of infestation. C, Overlap of susceptible response after 7 days of infestation and genetic differences after 1 day of infestation. The susceptible response after 1 day and the genetic differences after 7 days had only one common gene (not shown). 
induction of the ET defense pathway before aphid infestation would increase aphid resistance in soybean plants. Both $\mathrm{S}$ and $\mathrm{R}$ plants were sprayed with ACC (precursor to ET) or water as a control prior to aphid infestation and 1 day after infestation. Aphids were counted after 7 days of infestation to determine the effect of ET signaling on aphid population growth (Fig. 6). Because ET is a gas, the experiment was carried out in two different settings, one in which control and ACCtreated plants were in the same chamber and one in which control and ACC-treated plants were kept in separated chambers. The results showed that the plants sprayed with ACC had statistically the same number of aphids as the plants sprayed with water; consequently, ET induction did not affect aphid population growth in the resistant or susceptible cultivars (Fig. 6A and B, respectively). Similar results were obtained with either experimental set up. To determine the effectiveness of the ACC treatment, leaves were sampled immediately prior to spraying and 1 day after spraying, before aphid infestation. Induction of the ET defense pathway was confirmed using qPCR to test PR2 transcript levels in the leaves (Fig. 6C). PR2 (Glyma03g28850 gene) is known to be induced by ACC in soybean roots and shoots (Mazarei et al. 2007). These experiments indicate that ET induction prior to aphid infestation does not affect aphid performance on aphid-susceptible or aphid-resistant plants.
Effect of exogenous SA.

The hormone pathway analysis indicated a possible role for SA in the response to aphids. SA treatments similar to those used for ACC were performed to determine the role of SA in the plant-aphid interaction. An SA solution $(100 \mu \mathrm{M})$ was sprayed onto the leaves 1 day before and 1 day after aphid infestation. After 7 days of aphid infestation, the aphid populations on the SA-treated plants were compared with aphid populations on plants that were sprayed with a control solution. SA treatment had no effect on aphid performance when applied to $S$ plants (Fig. 7B). However, a significant increase in aphid resistance was observed in $\mathrm{R}$ plants that had been treated with the hormone (Fig. 7A). Expression of the SA marker gene $P R-1$ was used to confirm that the SA treatment was effective (Fig. 7C). This result suggests that $\mathrm{SA}$ is able to induce effective defense responses in $\mathrm{R}$ plants but this effect does not occur in $\mathrm{S}$ plants.

\section{Gene-silencing regulators.}

Small RNAs have an important role in controlling signaling pathways in plant-insect interactions, and altering the small RNA biosynthetic machinery results in changes in hormone signaling and plants with increased susceptibility to insect attacks (Pandey and Baldwin 2007; Pandey et al. 2008). Thus, we were particularly interested in a gene (Glyma04g17650) annotated as "gene-silencing regulator" that was induced in S plants to high

\begin{tabular}{|c|c|c|c|c|c|c|c|c|c|c|c|c|}
\hline & \multirow{2}{*}{\multicolumn{4}{|c|}{ All Genes }} & & & & & \multicolumn{4}{|c|}{ Marker Genes } \\
\hline & & & & & & synth & sis $\mathrm{Ge}$ & ne & |ATAF1 & ACCO & JAR1 & EDS1 \\
\hline & ABA & ET & JA & SA & ABA & ET & JA & SA & ABA & ET & JA & SA \\
\hline Susc-1 & 4.17 & 2.22 & 5.62 & 16.56 & 13.85 & 9.47 & 3.54 & 23.72 & 16.68 & 8.03 & 15.68 & 39.41 \\
\hline usc- 7 & 27.17 & 8.70 & 10.43 & 8.64 & 110.38 & 29.01 & 24.79 & -7.12 & 62.98 & -5.24 & 0.27 & 7.58 \\
\hline Res-1 & 0.00 & 0.00 & 0.00 & 0.00 & 0.00 & 0.00 & 0.00 & 0.00 & 0.00 & 0.00 & 0.00 & 0.00 \\
\hline Res-7 & 0.15 & 0.00 & 0.00 & 0.00 & 0.00 & 0.00 & 0.00 & 0.00 & 0.00 & 0.00 & 0.00 & 0.00 \\
\hline Gen-1 & 12.69 & 25.57 & 30.03 & 47.91 & 35.55 & 38.99 & 28.43 & 60.77 & 34.00 & 51.46 & 27.61 & 86.47 \\
\hline Gen-7 & 14.62 & -1.00 & -0.22 & -5.17 & 62.83 & -6.44 & 6.51 & -22.18 & 0.00 & -22.31 & 0.00 & 0.00 \\
\hline
\end{tabular}

Fig. 5. Analysis of changes in plant hormone-related genes in response to aphids. Values are scores that reflect changes in transcript levels of soybean genes associated with the hormones abscissic acid (ABA), ethylene (ET), jasmonic acid (JA), and salicylic acid (SA). The fold changes and statistical significance ( $q$ value) for the relevant genes are used to determine a score for each comparison. Positive scores indicate induction and negative scores indicate suppression. The three comparisons are susceptible response (Susc), resistance response (Res), and genetic differences (Gen) and the two time points are day 1 and day 7. Initially, all genes associated with the hormones were included (left panel). In the center panel, only biosynthesis genes are considered and, in the right section, only hormone signaling marker genes are considered. In all scoring, only genes with absolute fold change above 1.20 and $q$ values less than 0.20 had an effect. A three-color scale was used to highlight the scores: blue for negative (suppression), white for no change, and yellow for positive (induction).
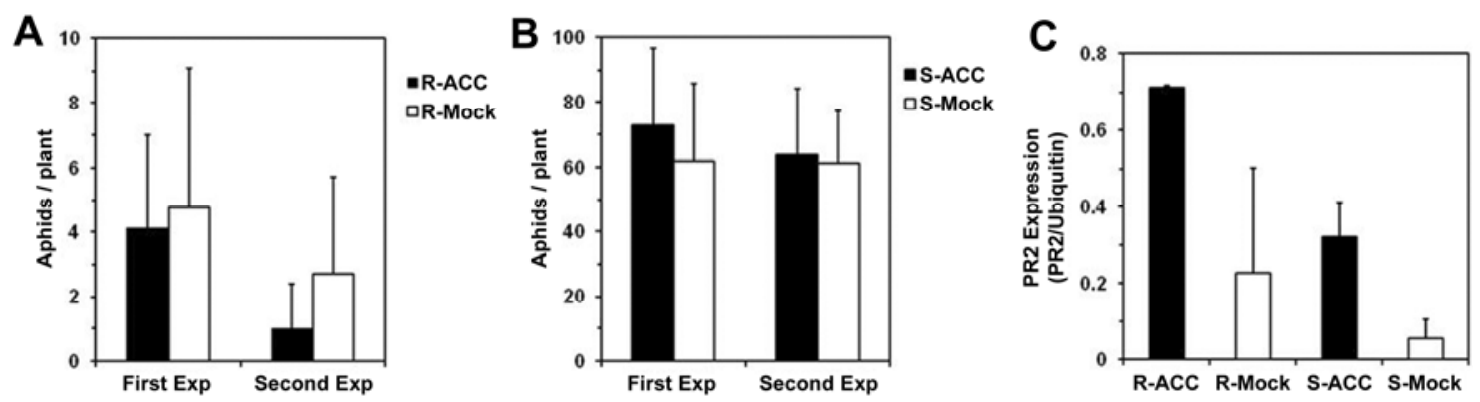

Fig. 6. Ethylene induction does not affect susceptibility or resistance of soybean plants to soybean aphids. Two experiments tested the effect of ethylene induction on aphid-resistant (R) and aphid-susceptible (S) lines after 7 days of aphid infestation. Plants were sprayed with a 1 mM 1-aminocyclopropane-1-carboxylic acid solution (ACC) or water (Mock) the day before and the day after aphid infestation. In the first experimental set-up, all the plants were in the same growth chamber whereas, in the second experimental set-up, the ACC and Mock plants were separated into different growth chambers. Each plant was initially infested with five aphids. A, Final aphid counts per resistant plant after 7 days of infestation. B, Final aphid counts per susceptible plant after 7 days of infestation. The ACC treatment was not significantly different $(t$ test) from the Mock treatment for any line or experimental setup. C, Ethylene induction was confirmed by quantitative polymerase chain reaction results showing that the leaves of ACC-treated plants have higher PR2 (GmaAffx.93073.1.S1_s_at) levels than Mock plants $24 \mathrm{~h}$ after the first spraying, prior to aphid infestation. 
levels in response to aphid colonization (Fig. 8). This transcript is a homolog to the tomato $\mathrm{rgs}-\mathrm{CaM}$ gene, whose over-expression suppresses posttranscriptional gene silencing in tobacco (Anandalakshmi et al. 2000). Further analysis of the soybean genome resulted in the identification of seven highly similar genes belonging to the same family (not shown). Among those, a second homolog (Glyma04g17710) was represented in the Soybean GeneChip, and was also significantly induced by aphids on day 7 in $\mathrm{S}$ plants. An additional soybean aphid response experiment was done in which plants were sampled after 21 days of aphid colonization. qPCR was used to confirm the microarray results for these two soybean genes and to also analyze transcript levels after 21 days of aphid infestation. The results for the susceptible response confirmed the induction of the gene-silencing regulators at day 7 and an even greater induction at day 21 (Fig. 8). The small increases observed in the resistance response were not statistically significant.

\section{DISCUSSION}

Our microarray experiment is the second large-scale transcript profiling study of soybean responses to the soybean aphid. The first study used cDNA microarrays to determine the transcriptional response in aphid-resistant and aphid-susceptible soybean plants 6 and 12 hpa (Li et al. 2008). Our study analyzed longer infestation times (24 and $168 \mathrm{~h}$ ) and used Affymetrix GeneChip Soybean Genome Arrays to profile the transcriptome. We used different soybean cultivars than those used by Li and associates (2008); however, the source of resistance was the Ragl gene in both cases. Analysis of the two experiments shows a more complete picture of the transcriptional response to aphids. The susceptible and resistance response profiles over four time points using data from both experiments are illustrated in Figure 9.

$\mathrm{R}$ plants respond quickly to aphids and, after $24 \mathrm{~h}$, we found that this response is largely finished. However, Li and associates (2008) indicated that three genes (PRIa, P21, and MMP2) were still upregulated at $24 \mathrm{~h}$ and beyond. These differing results could be explained by the use of different resistant cultivars and different sampling techniques. We sampled the entire leaf (third trifoliate), whereas the previous study sampled small unifoliate leaf circles; thus, the first experiment may have found a localized response that was not significant in our analysis because our samples were diluted. In addition, we set a very stringent cutoff for DE gene classification. However, the resistance response is clearly not over by the $24 \mathrm{~h}$ time point because we did find DE gene sets, including cell-wall-, JA-, and ET-related transcripts, some of which were also identified in the cDNA microarray analysis. Moreover, it is likely the Affymetrix GeneChip Soybean Genome Array does not cover some induced genes, and our statistical cutoffs for individual transcripts are set to prevent false discovery, not false negatives. Despite the differences in methodology, our results, along with the cDNA microarray study, indicate that the resistant response happens quickly, mostly approximately 6 and $12 \mathrm{~h}$ after the beginning of the aphid infestation.

The presence of genes differentially regulated between our related resistant and susceptible cultivars in the absence of

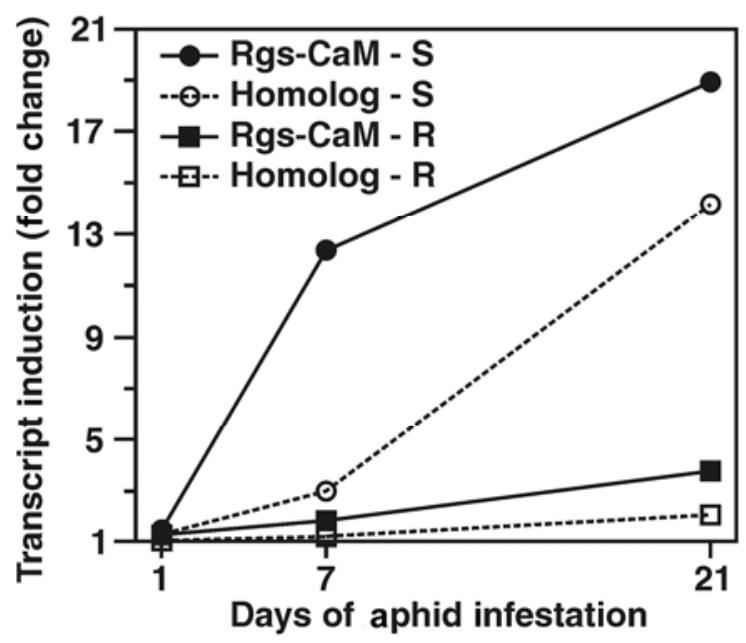

Fig. 8. Induction of transcripts corresponding to regulator of gene silencingcalmodulin $(\mathrm{rgs}-\mathrm{CaM})$ by aphids in susceptible response. Both $\mathrm{Rgs}_{\mathrm{S}} \mathrm{CaM}$ (GmaAffx.3696.1.S1_at) and a homolog of Rgs-CaM (Gma.15972.1.A1_at) show significant positive fold changes in the susceptible response after 7 and 21 days of aphid infestation (Rgs-CaM-S, Homolog-S). The resistance responses are positive but statistically insignificant (Rgs-CaM-R, Homo$\log -\mathrm{R})$.
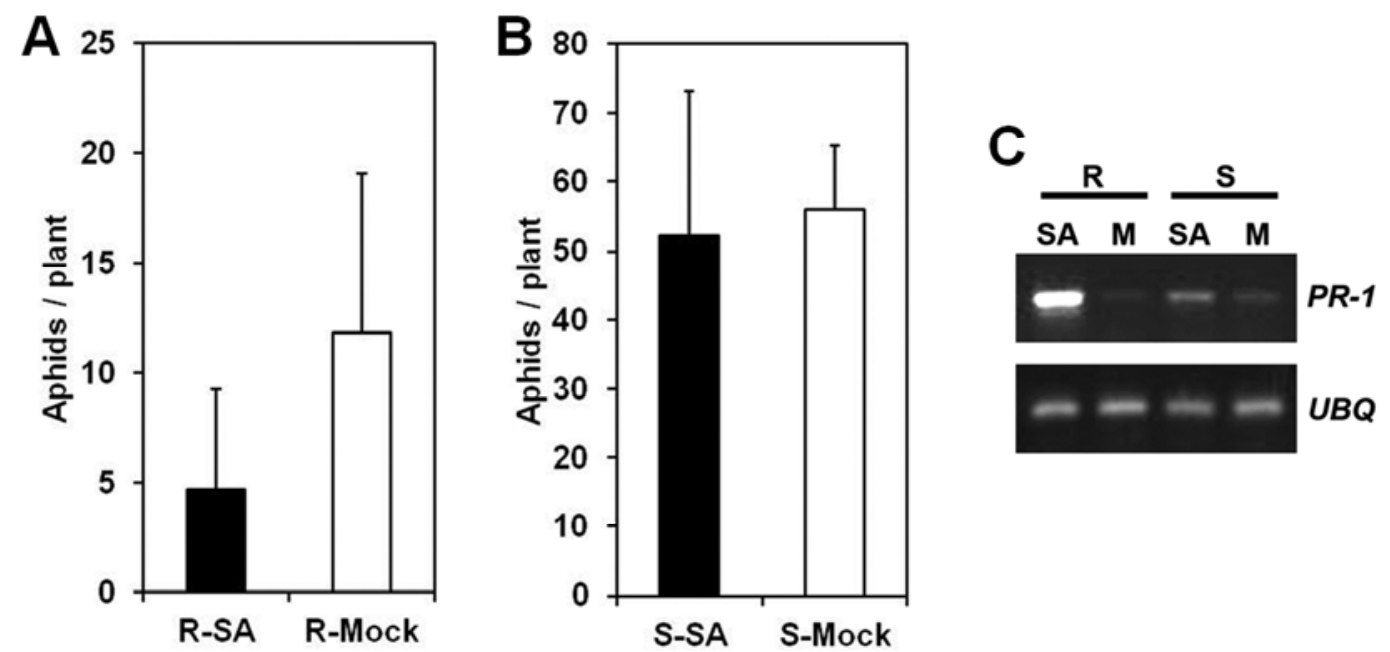

Fig. 7. Salicylate treatment affects aphid performance on resistant plants. Plants were sprayed with $100 \mu \mathrm{M}$ salicylic acid (SA) or a control solution (Mock) the day before and the day after aphid infestation. SA and Mock plants were separated into different growth chambers. Each plant was initially infested with five aphids. A, Final aphid counts per resistant plant after 7 days of infestation. SA-treated plants show a significant difference $(t$ test, $P<0.05)$ in the number of aphids compared with Mock plants. B, Final aphid counts per susceptible plant after 7 days of infestation. No significant differences were observed between treatments for this soybean line. C, SA effect was confirmed by reverse-transcribed polymerase chain reaction results showing that the leaves of SA-treated plants have higher PR1 (Glyma13g32530) levels than Mock plants $24 \mathrm{~h}$ after the first spraying, prior to aphid infestation. 
aphids suggests that partial constitutive resistance may be present in $\mathrm{R}$ plants, in addition to the fast induced resistance response. $\mathrm{R}$ plants showed higher levels of expression of defense-related transcripts than $\mathrm{S}$ plants prior to aphid infestation, whereas $\mathrm{S}$ plants did not activate these same genes until after an aphid attack. The existence of constitutive differences between the susceptible and resistant cultivars used in our study was also observed through an amino acid profiling study (Chiozza et al. 2010). In that study, we observed that, in the absence of aphids, the amino acid profile of $\mathrm{R}$ plants is different from the profile observed in S plants. After infestation, amino acid levels changed in S plants, reaching the levels observed in noninfested $\mathrm{R}$ plants, in a manner that resembles the gene expression pattern obtained in our microarray analysis. Constitutive resistance response has also been described in an enzyme activity study of aphid-susceptible and -resistant cultivars of wheat (Han et al. 2009) and in a transcript profiling analysis of barley cultivars susceptible or partially resistant to Rhopalosiphum padi (Delp et al. 2009). The cDNA microarray study found a few constitutive defense-related genes, including the disease $R$ gene $R p g 1-b$, which is also marginally upregulated (+1.42 fold, $q=0.166)$ in our R plants without aphids. Rpg 1-b confers resistance to some strains of $P$. syringae (Ashfield et al. 2003).

Overall, we found hundreds of transcriptional differences between the resistant and S plants without aphids, and many of these genes also appeared in the susceptible response (Fig. 4). Many of the overlapping genes were defense related, leading us to propose the partial constitutive resistance hypothesis. However, we also have unexpected results regarding genetic differences. Out of 424 genes involved in the genetic differences, only 25 are significantly different at both time points. Furthermore, many DE genes are upregulated on day 1 but downregulated on day 7. The cause of these inconsistencies might be priming, "a physiological process by which a plant prepares to more quickly or aggressively respond to future biotic or abiotic stress" (Frost et al. 2008). In plant-insect interactions, priming is triggered by volatile organic compounds

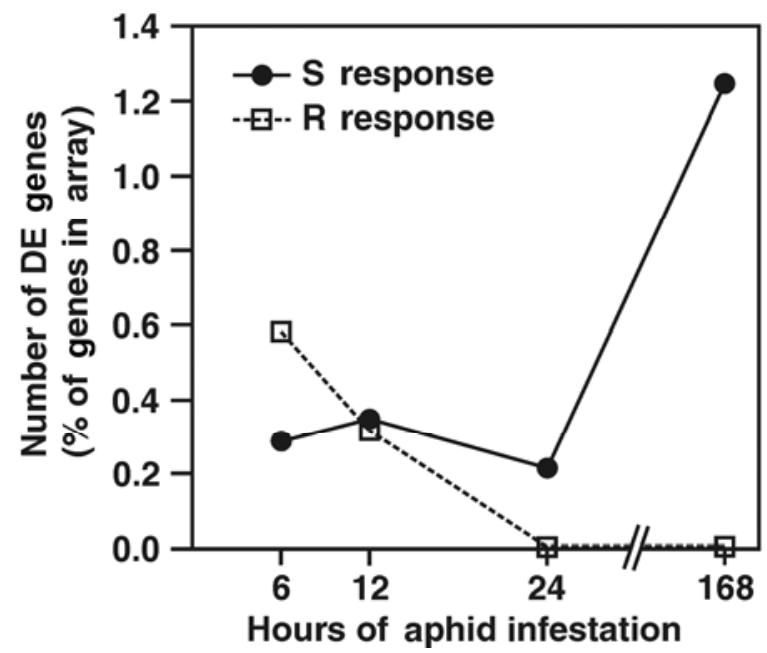

Fig. 9. Aphid response profiles over four time points. Results from the cDNA microarrays (Li et al. 2008) and Affymetrix microarrays are plotted to show the aphid-resistant ( $\mathrm{R}$ Response) and aphid-susceptible ( $\mathrm{S} \mathrm{Re}$ sponse) soybean plants' responses to aphids over four time points. The 6- and 12-h data are from the cDNA microarrays and the 24- and 168-h (7-day) data are from our Affymetrix microarrays. In order to compare the two experiments, the number of differentially expressed (DE) genes is shown as a percentage of the total number of soybean genes in the array. Also note that the two experiments used different criteria to determine differential expression.
(Engelberth et al. 2004; Frost et al. 2008). In our analysis, aphid-infested and uninfested plants were kept in the same growth chamber during the experiment; thus, it is possible that volatile organic compounds emitted by aphid-infested plants induced defense-related transcriptional changes in nearby control plants without aphids. This hypothesis implies that $\mathrm{R}$ and $S$ plants have a differential response to priming, without direct contact with aphids. Fewer genes are upregulated in $\mathrm{R}$ plants in the absence of aphids on day 7 than on day 1 . Among those, many correspond to defense-related genes, including those involved in the response to insects, and genes involved in the response to chemicals. This observation could suggest that the priming response is attenuated after some time in the absence of actual injury, likely due to the fitness cost of priming (Frost et al. 2008). Alternatively, R plants may respond to priming faster than S plants; thus, the difference at day 1 is large but, by day 7 , the $\mathrm{S}$ plants have partially caught up with the $\mathrm{R}$ priming response and the difference is smaller. Intriguingly, methyl-SA is one of the main volatiles produced by aphid-infested soybean (Zhu and Park 2005), and R plants seem to be more responsive to SA treatments than S plants (Fig. 7C). These observations provide some support to the notion that Ragl may confer differential response to priming. It is important to note that some of the genetic differences, such as the upregulation of the ABA pathway at both time points, evident in our hormone pathway analysis, do not appear to be the result of priming. Also, our experimental set-up was not designed to investigate the presence of priming; thus, this tentative hypothesis needs to be directly studied in subsequent experiments.

$\mathrm{S}$ plants respond much more slowly to aphid colonization than R plants (Fig. 9), and this response involves hundreds of genes, several of which are also induced by $P$. syringae. It is difficult to elucidate the effective defense response against aphids from decoy responses and damage repair responses. However, if the aphid defense is similar to $P$. syringae defense as proposed by $\mathrm{Li}$ and associates (2008), then the induction of ET production could be part of a decoy response favoring aphid performance. Some strains of $P$. syringae can produce ET, and these strains are much more virulent than non-ET-producing mutants. This virulence difference disappears on ET-insensitive soybean plants (Weingart et al. 2001), indicating that ET is produced by the bacteria to suppress effective plant defenses. Furthermore, our ET induction experiments indicate that inducing ET production prior to and during aphid infestation does not affect aphid population sizes after 7 days of infestation. Therefore, the ET response alone is not an effective aphid defense.

Another possible decoy response could be the strong induction of ABA-related genes in the susceptible response, especially at day 7. In Arabidopsis, there is evidence that $P$. syringae induces ABA in order to suppress the effective defense response controlled by SA (De Torres Zabala et al. 2009). Our pathway analysis (Fig. 5) indicated that, after 1 day of infestation, SA signaling was highly induced but, after 7 days, ABA had surpassed SA as the dominant phytohormone. Therefore, it is possible that the rise of the ABA response suppressed the SA response in plants under sustained aphid colonization. This hypothesis could explain the results observed in our SA treatment experiment. SA is able to establish effective defenses in $\mathrm{R}$ plants but the aphid-induced increase in $\mathrm{ABA}$ response blocks this effect on S plants.

JA is often the predominant hormone defense against insects (Howe and Jander 2008). We found that JA biosynthesis is induced in $S$ plants at 1 and 7 days of infestation. Interestingly, biosynthesis of JA is followed by induction of the JA-responsive genes on day 1 but this does not occur on day 7, when expression of JA-responsive genes is not observed even though 
JA biosynthesis is higher than on day 1. Thus, it is possible that JA signaling is also repressed by aphids as a way to suppress effective defense responses. This strategy has already been proposed in other phloem feeder-plant interactions. Arabidopsis plants infested with silverleaf whitefly (SLWF) induce SA-regulated RNAs locally and systemically, whereas JAregulated RNAs are unchanged or decline. However, when the nprl mutant, deficient in SA-regulated defenses, is treated with methyl jasmonate, SLWF nymph development is severely delayed. These results demonstrate that JA controls defenses that actively affect whitefly development, and indicate that this phloem feeder is able to suppress an effective defense response (Walling 2008).

Analysis of aphid-induced changes in soybean fatty acid levels suggest that, at least in part, aphids reduce JA signaling through inhibition of JA biosynthesis (Kanobe et al. submitted). We found that aphid colonization results in a decrease in polyunsaturated fatty acids (linoleic and linolenic acid) in soybean leaves. Linolenic acid is used by plants as the precursor for JA biosynthesis through the oxilipin pathway; reduction of available linolenic acid would then result in limited production of JA, even if the expression of biosynthetic genes is upregulated.

An alternative or additional mechanism for suppression of an effective JA response may be provided by small RNAs. Although the involvement of small RNAs in the regulation of plant-aphid interactions has not been reported, Pandey and Baldwin (2007) found that expression of RNA-dependent RNA (RdR) polymerase $R d R l$ was highly induced in tobacco plants treated with caterpillar oral secretions. Plants with reduced levels of $R d R I$ grew normally but failed to accumulate nicotine in response to insect attacks and were highly susceptible to caterpillar feeding. Large changes in the small RNA transcriptome of tobacco were observed in response to caterpillar feeding (Pandey et al. 2008), and identification of targets of differentially regulated miRNAs indicated an important role of miRNAs in regulation of the JA response. $R d R l$ silencing had a large effect on the small RNA transcriptome as expected, and plants with deficient $R d R l$ had reduced JA responses and enhanced ET signaling.

Our observation that a regulator of gene silencing, $r g s-C a M$, is induced by aphids fits well with the idea that aphids can suppress the normal defense response against other herbivores through inhibition of the production of small RNAs. Rgs-CaM can block production of siRNAs; overexpression of this protein in tobacco plants resulted in complete inhibition of transgene silencing and lack of accumulation of small RNAs (Anandalakshmi et al. 2000). It was proposed that $\mathrm{rgs}^{-\mathrm{CaM}}$ blocks production of small RNAs at the level of Dicer activity (i.e., downstream of the action of RdRs) (Vaucheret et al. 2001). Thus, an increase in $\mathrm{rgs}$-CaM, which can negatively affect gene silencing, could lead to changes in the small RNA transcriptome similar to those found in $R d R l$-deficient plants. This would lead to an inhibition of JA signaling and increase in ET signaling, two of the main results observed in our microarray analysis. Consequently, we hypothesize that aphids can suppress effective defense responses by altering the small RNA transcriptome. This hypothesis is further supported by the finding that other phloem feeders known to suppress effective defense responses also induce $\mathrm{rgs}-\mathrm{CaM}$ in other systems. Analysis of previously published microarray data showed that an rgs-CaM homolog is induced by SLWF in Arabidopsis (Kempema et al. 2007) and another member of the family is induced by the cabbage aphid (Brevicoryne brassicae), also in Arabidopsis (Kuśnierczyk et al. 2008).

Strong support for our hypothesis suggesting that aphids are able to block effective defenses against herbivores is provided by the observations reported by McCarville and associates
(2012). In a microplot experiment that analyzed the plant response to multiple pests, it was found that soybean cyst nematode reproduction rates increase fourfold in plants that are colonized with soybean aphids when compared with plants only infected with nematodes. This increase in nematode reproduction could be the result of defense suppression by aphids. We found that aphid infestation results in increased transcription of a WRKY transcription factor homolog to Arabidopsis WRKY23. The same WRKY is induced in soybean cyst nematode feeding sites in soybean and sugar beet nematode feeding sites in Arabidopsis. Moreover, nematode performance is decreased in Arabidopsis plants with reduced levels of WRKY23, suggesting that nematodes induce WRKY23 expression to reduce defenses and increase colonization success (Grunewald et al. 2008). A similar role can be proposed for the soybean homologs during aphid colonization, and could explain the effect of aphids on nematode reproduction.

Our results, combined with those from $\mathrm{Li}$ and associates (2008), suggest that SA and JA may have a role in the establishment of effective defense responses against aphids, particularly in R plants. On the other hand, ABA- and ET-related genes show higher induction than SA in the ineffective susceptible response. These hormones may trigger decoy defenses that suppress SA and JA, as has been shown in other plants (Brooks et al. 2005; De Torres Zabala et al. 2009; Uppalapati et al. 2007). Interestingly, both resistant and susceptible responses overlap with responses to $P$. syringae ( $\mathrm{Li}$ et al. 2008), a bacterial pathogen known for its induction of decoy defenses and also known to be effectively controlled by an SA-related hypersensitive response (Tao et al. 2003; Zou et al. 2005). A role for SA as part of an effective defense against soybean aphids is further supported by the finding that one of the main volatiles emitted by infested plants is methyl-SA, which attracts one of the major predators of aphids, the lady beetle (Zhu and Park 2005).

More work is needed to determine whether SA is effective against soybean aphids and the role of JA and small RNAs, and to elucidate other aspects of the aphid response. External hormone treatments may not fully reflect the effect of internal hormone pools; thus, alternative approaches such us virusinduced gene silencing targeting individual hormone pathways are necessary. Defense priming effects might significantly affect aphid resistance; thus, primed and unprimed plants could be compared to determine the role of the priming in this interaction and a putative differential response to priming by $\mathrm{R}$ and $\mathrm{S}$ plants. Also, because aphids can infest a plant for months, longer time points should be studied to fully understand the response to aphid colonization.

\section{MATERIALS AND METHODS}

\section{Plant growth conditions and experimental design for microarray analysis.}

Soybean (G. $\max (\mathrm{L}$.) Merr.) plants were grown in a growth chamber with a constant temperature of $25^{\circ} \mathrm{C}$ and a 16-h photoperiod. Seed were sown in SB300 Universal bark-based growing mix (Sun Gro Horticulture, Vancouver, BC, Canada) in $15-\mathrm{cm}$-diameter green plastic pots. Rhizobium powder $(B$. japonicum) was applied to each pot during planting.

A full-factorial experiment with three factors (soybean variety, aphid treatment, and infestation duration) was used, with six plants per treatment. The two soybean varieties, provided by B. Diers (University of Illinois, Urbana-Champaign), were aphidresistant LD05-16060 (R) with the Ragl gene and aphid-susceptible SD01-76R (S). The genetic relation between these lines was described previously (Chiozza et al. 2010). The aphid treatments were "with" (aphid plants) or "without" (control plants). The infestation duration was either 1 day (day 1 plants) or 7 
days (day 7 plants). The plant locations in the growth chamber were based on a split plot randomized complete block design. The whole-plot factor was aphid treatment. Within each plot there were six complete blocks, and plants were randomized within each block.

\section{Aphid infestation.}

A colony of soybean aphids (A. glycines Matsumura [Hemiptera: Aphididae]) living on SD01-76R plants were kept in a separate growth chamber. These aphids were known to be controlled by the Rag1 gene. After all the day 7 plants had reached the V3 growth stage, an infested plant from the colony was brought to the experiment growth chamber and aphids were transferred to day 7 aphid plants in the experiment. Using a fine-tip paintbrush, 10 aphids were applied to the adaxial surface of each leaflet of the third trifoliate leaves (30 aphids per plant). At this time, all the plants were individually covered with nets (5-gal. paint strainers) (Trimaco LLC, Durham, NC, U.S.A.) secured with rubber bands around the pot. The nets prevented almost all aphid movement to and from different plants and they decreased the light intensity 10 to $20 \%$. Aphids were able to move freely on each plant. Five days after infestation of the day 7 plants, aphids were applied to the day 1 plants in the same manner. Prior to sampling, the aphids were counted on all plants. A $t$ test was used to compare means between treatments.

\section{Leaf sampling, RNA isolation, and microarray analysis.}

Third trifoliate leaves were sampled after 1 or 7 days of aphid infestation. Each sample consisted of the third trifoliate leaves pooled from two plants (three samples per treatment). Immediately prior to sampling, the aphids on the third trifoliates of the aphid plants were gently removed using a soft paintbrush. The brushing action was simulated with the same brush on control plants prior to their sampling. Samples were ground under liquid nitrogen using a mortar and pestle, and the ground tissue samples were stored in a $-80^{\circ} \mathrm{C}$ freezer.

Total RNA was isolated from the frozen ground leaf tissue using the RNeasy plant mini kit (Qiagen, Valencia, CA, U.S.A.). RNA quantity and quality were determined using a NanoDrop ND 1000 spectrophotometer (NanoDrop Technologies, Wilmington, DE, U.S.A.) and an RNA 6000 Nano LabChip (Agilent Technologies, Palo Alto, CA, U.S.A.) with a 2100 Bioanalyzer (Agilent Technologies). RNA concentration was adjusted to 0.73 to $1.00 \mu \mathrm{g} / \mu \mathrm{l}$. GeneChip Soybean Genome Arrays (Affymetrix, Santa Clara, CA, U.S.A.) were used to measure mRNA abundance in each of the 24 samples. The Iowa State University GeneChip Facility labeled, hybridized, and scanned the arrays, following Affymetrix's standard protocol. GeneChip Operation Software was used for image data collection, as well as cell intensity and chip data file generation.

\section{Statistical analysis of microarray data.}

The $\mathrm{R}$ programming language for statistical computing (version 2.6.2), specifically the Bioconductor package (Gentleman and Carey 2005) and affy package (Gautier et al. 2004), was used throughout the statistical data analysis. Day 1 and day 7 data were analyzed separately. Raw intensities were normalized using the GCRMA method (Irizarry et al. 2003; Wu et al. 2004). After normalization, all non-soybean probe sets were filtered out. The aphid plant samples were compared with the control plant samples within each genotype to determine the susceptible response and resistance response to aphids. Also, the resistant control plant samples were compared with the susceptible control plant samples to determine effect of genotype on transcript levels. A mixed linear model was created and fit for each probe set and comparison (Smyth 2004). In the model, the aphid treatment coefficient was multiplied times the $\log _{10}$ of the final aphid count to account for different aphid population sizes on replicates. For hypothesis testing, a moderated $t$ test (Smyth 2004) used the linear model to determine the $P$ values, which were then converted to $q$ values (Storey et al. 2004) to control the multiple testing error. The $q$ values enabled us to estimate the FDR. Fold changes were calculated using the means of the normalized intensity values for the experimental and control treatments for each comparison. Differential expression was determined using the following cutoffs: $P \leq 0.0001$ and $q \leq 0.04(\mathrm{FDR}=4 \%)$ and the absolute value of the fold change $\geq 2$. The gene set analysis used 455 Gene Ontology biological processes (Ashburner et al. 2000), including defense-related processes, as sets and implemented the GSA method (Efron and Tibshirani 2007) with a maximum 5\% FDR to determine $\mathrm{DE}$ gene sets for each comparison. The clustering analysis involved all DE probe sets in all comparisons for both time points. These probe sets were grouped, based on their aphid response and genetic components ( $\log _{2}$ difference values), for both time points from the linear models, according to the iterative K-medoid method (Rousseeuw 1987), using a Euclidean distance metric. The optimal number of clusters was determined by finding the maximum average silhouette width. The cluster heat map was created using an Excel (Microsoft, Redmond, WA, U.S.A.) macro using the Visual Basic programming language. Positive coefficients above 0.6 are shown in yellow (Fig. 2) and negative coefficients below -0.6 are shown in blue. The color saturation is proportional to the absolute value of the coefficient up to a maximum saturation for coefficients whose absolute values are $\geq 3$. Values between 0.6 and -0.6 are white.

\section{Gene annotations.}

The Affymetrix array probe sets were assigned to genes and the genes were annotated initially by using the Soybase and the Soybean Breeder's Toolbox SoyChip Annotations. DE genes were defined by our group as soybean genes that have at least one matching DE probe set. GeneChip Soybean Genome Array probe set annotations (Affymetrix) were also used in conjunction with the Soybase annotations.

\section{RT-PCR.}

The same RNA samples used for microarray analysis, along with RNA newly isolated in the same manner, were used for RT-PCR to confirm the microarray results. The iScript Select cDNA Synthesis kit (Bio-Rad Laboratories, Hercules, CA, U.S.A.) was used for first-strand synthesis of cDNA made from total RNA samples. Oligonucleotide primer sequences for each gene of interest were designed using our proprietary PrimerDesigner software, which utilizes the National Center for Biotechnology Information $\mathrm{C}++$ Toolkit and the soybean genome. Primers were synthesized by IDT (Coralville, IA, U.S.A.). PCR reaction was performed using GoTaq Green Master Mix (Promega Corp., Madison, WI, U.S.A.). PCR products were analyzed in $1 \%$ agarose gels. cDNA controls for RT-PCR were run using primers for the reference gene ubiquitin (Glyma20g27950, which is unaffected by aphid treatment and genotypic differences).

\section{q-PCR.}

qPCR was used for further confirmation of microarray results. Primers were designed and synthesized in the same manner as for RT-PCR. Total RNA samples were treated with DNase I using Turbo DNA-free (Ambion, Austin, TX, U.S.A.) and then split into two groups: RT+ and RT-. The RT+ samples were used for first-strand cDNA synthesis with the iScript Select cDNA Synthesis kit (Bio-Rad Laboratories). The RT- 
samples went through the same procedure, except water was substituted for RT. qPCR was run using ABsolute QPCR SYBR Green Mix (Thermo Fisher Scientific, Waltham, MA, U.S.A.) in a Stratagene Mx4000 Multiplex Quantitative PCR System (Agilent Technologies, Santa Clara, CA, U.S.A.). All of the RT+ and RT- samples were tested with a ubiquitin reference gene and the gene of interest. Parameters were $15 \mathrm{~min}$ at $95^{\circ} \mathrm{C}$ and 40 cycles of $15 \mathrm{~s}$ at $95^{\circ} \mathrm{C}$ for denaturation, $30 \mathrm{~s}$ at $56^{\circ} \mathrm{C}$ for primer annealing, and $30 \mathrm{~s}$ at $72^{\circ} \mathrm{C}$ fir extension. Stratagene $\mathrm{Mx} 4000$ software (Agilent) was used to set the threshold and calculated raw quantification cycle values. The Pfaffl method (Pfaffl 2001) was used to determine the foldchange differences in transcript expression levels for each comparison. The efficiency for each gene was determined using a standard curve based on the dilution series. In cases where transcript levels are shown, cycle times were converted to quantities using the standard curve. Transcript levels for each sample were calculated by dividing the gene of interest quantity by the reference gene quantity. A $t$ test was used to compare means between treatments.

\section{Comparisons to other microarray experiments.}

The soybean aphid microarray experiment of Li and associates (2008) used cDNA arrays. BLASTN was used to search the soybean genome for genes matching $\left(e \leq 10^{-10}\right)$ all of the target sequences (expressed sequence tags) for cDNA probes that were DE in that experiment. If multiple probe sets matched a single gene, the results (fold changes) were averaged. Genes with results from both $\mathrm{Li}$ and associates (2008) and our day 1 time point were compared.

\section{Hormone pathway analysis.}

Genes associated with the hormones ABA, ET, JA, and SA were used to analyze these hormones' pathway responses to aphid infestation. A pathway score was assigned to each pathway for each experiment and comparison. Only genes that had an absolute fold change $\geq 1.2$ and a $q$ value $\leq 0.20$ were considered. Then fold changes were converted to $\log _{2}$ differences and weighted based on significance ( $1-q$ value). These weighted $\log _{2}$ differences were averaged, and that average was multiplied times 100 to get the final pathway score. A heat map was created using Excel (Microsoft). Positive scores are yellow, zero is white, and negative scores are shown in blue (Fig. 5). The color saturation is proportional to the absolute value of the score up to a maximum saturation for scores whose absolute values are $\geq 70$. A full description of the method used for pathway analysis was given by Studham and MacIntosh (2012).

\section{ET and SA treatment experiments.}

For ET, two experiments (full-factorial with two factors: genotype and spray treatment) were used. The genotypes were the same as in the microarray experiments (susceptible and resistant). Spray treatment was either water (control) or ACC. Each experiment had 10 plants per treatment, plus extra plants to analyze the effectiveness of the hormone treatment. Plants were grown in the same manner as the microarray experiment. When plants reached the V4/V5 growth stage, plants were sprayed with water or ACC (day 0). For the second experiment, the water and ACC plants were separated into two different growth chambers before spraying. At this time, a few plants were sampled in the same manner as microarray plants and sampled plants were removed. Then, the abaxial and adaxial surfaces of all leaves except for the third trifoliate (temporarily covered) were sprayed with either water or $1 \mathrm{mM} \mathrm{ACC}$ solution. A SureShot Atomizer Sprayer (Milwaukee Sprayer, Menomonee Falls, WI, U.S.A.) was used to deliver a fine layer of water or ACC onto the leaf. Typically, $8 \mathrm{ml}$ of solution was used to spray each plant. Another set of samples was obtained $24 \mathrm{~h}$ later (day 1) using the remaining extra plants. Treatment plants were then infested with five aphids descended from a single female (same cohort) in the same manner as the microarray experiments, and nets were put on the plants. On day 2, the plants were sprayed again, the same way as on day 0 . On day 8 , the aphids were counted on all the plants. A $t$ test was used to compare means between treatments. Tissue from the extra plants sampled at day 0 and day 1 was processed for RNA isolation and $\mathrm{qPCR}$ analysis as described above. $P R 2$ expression was used to determine effectiveness of the ET treatment.

For SA treatments, three experiments were performed as for the second ET experiment. Mock plants were sprayed with a control solution $(0.1 \%$ ethanol, $\mathrm{pH} 4.4$ to 4.7$)$ and the induced plants were sprayed with a similar solution with $100 \mu \mathrm{M}$ SA. Plants were sprayed at the V3 growth stage at day 0 and at day 2. All plants were infested with nine aphids. On day 8 , the aphids were counted on each plant. A $t$ test was used to compare means between treatments. Extra plants were sampled at day 0 and day 1 as described. RT-PCR analysis of PR1 expression was used to determine effectiveness of the SA treatment.

\section{ACKNOWLEDGMENTS}

This work was supported by grants from the Iowa State University Plant Sciences Institute and the Iowa Soybean Association to G. C. MacIntosh. We thank P. Liu for her assistance with the statistical analysis of microarray data; F. Avendaño, M. McCarville, and S. Liu for their assistance with the aphid colony; M. Graham for her assistance with soybean gene annotations; and J. Dickerson for her advice regarding experimental design and statistical analysis.

\section{LITERATURE CITED}

Anandalakshmi, R., Marathe, R., Ge, X., Herr, J. M., Mau, C., Mallory, A., Pruss, G., Bowman, L., and Vance, V. B. 2000. A calmodulin-related protein that suppresses posttranscriptional gene silencing in plants. Science 290:142-144.

Ashburner, M., Ball, C. A., Blake, J. A., Botstein, D., Butler, H., Cherry, J. M., Davis, A. P., Dolinski, K., Dwight, S. S., Eppig, J. T., Harris, M. A., Hill, D. P., Issel-Tarver, L., Kasarskis, A., Lewis, S., Matese, J. C., Richardson, J. E., Ringwald, M., Rubin, G. M., and Sherlock, G. 2000. Gene Ontology: Tool for the unification of biology. Nat. Genet. 25:2529.

Ashfield, T., Bocian, A., Held, D., Henk, A. D., Marek, L. F., Danesh, D., Peñuela, S., Meksem, K., Lightfoot, D. A., Young, N. D., Shoemaker, R. C., and Innes, R. W. 2003. Genetic and physical localization of the soybean $r p g 1-b$ disease resistance gene reveals a complex locus containing several tightly linked families of NBS-LRR Genes. Mol. PlantMicrobe Interact. 16:817-826.

Asselbergh, B., De Vleesschauwer, D., and Hofte, M. 2008. Global switches and fine-tuning-ABA modulates plant pathogen defense. Mol. Plant-Microbe Interact. 21:709-719.

Beckendorf, E. A., Catangui, M. A., and Riedell, W. E. 2008. Soybean aphid feeding injury and soybean yield, yield components, and seed composition. Agron. J. 100:237-246.

Belostotsky, D. A., and Sieburth, L. E. 2009. Kill the messenger: mRNA decay and plant development. Curr. Opin. Plant Biol. 12:96-102.

Blande, J. D., Korjus, M., and Holopainen, J. K. 2010. Foliar methyl salicylate emissions indicate prolonged aphid infestation on silver birch and black alder. Tree Physiol. 30:404-416.

Brooks, D. M., Bender, C. L., and Kunkel, B. N. 2005. The Pseudomonas syringae phytotoxin coronatine promotes virulence by overcoming salicylic acid-dependent defences in Arabidopsis thaliana. Mol. Plant Pathol. 6:629-639.

Bu, Q., Jiang, H., Li, C.-B., Zhai, Q., Zhang, J., Wu, X., Sun, J., Xie, Q., and Li, C. 2008. Role of the Arabidopsis thaliana NAC transcription factors ANAC019 and ANAC055 in regulating jasmonic acid-signaled defense responses. Cell Res. 18:756-767.

Casaretto, J. A., Zúñiga, G. E., and Corcuera, L. J. 2004. Abscisic acid and jasmonic acid affect proteinase inhibitor activities in barley leaves. J. Plant Physiol. 161:389-396.

Chaman, M. E., Copaja, S. V., and Argandona, V. H. 2003. Relationships 
between salicylic acid content, phenylalanine ammonia-lyase (PAL) activity, and resistance of barley to aphid infestation. J. Agric. Food Chem. 51:2227-2231.

Chiozza, M. V., O’Neal, M. E., and MacIntosh, G. C. 2010. Constitutive and induced differential accumulation of amino acid in leaves of susceptible and resistant soybean plants in response to the soybean aphid (Hemiptera: Aphididae). Environ. Entomol. 39:856-864.

Crompton, D. S., and Ode, P. J. 2010. Feeding behavior analysis of the soybean aphid (Hemiptera: Aphididae) on resistant soybean 'Dowling'. J. Econ. Entomol. 103:648-653.

Delp, G., Gradin, T., Åhman, I., and Jonsson, L. 2009. Microarray analysis of the interaction between the aphid Rhopalosiphum padi and host plants reveals both differences and similarities between susceptible and partially resistant barley lines. Mol. Genet. Genomics 281:233-248.

De Torres Zabala, M., Bennett, M. H., Truman, W. H., and Grant, M. R 2009. Antagonism between salicylic and abscisic acid reflects early host-pathogen conflict and moulds plant defence responses. Plant J. 59:375-386.

De Vos, M., and Jander, G. 2009. Myzus persicae (green peach aphid) salivary components induce defence responses in Arabidopsis thaliana. Plant Cell Environ. 32:1548-1560.

De Vos, M., Kim, J. H., and Jander, G. 2007. Biochemistry and molecular biology of Arabidopsis-aphid interactions. Bioessays 29:871-883.

Diaz-Montano, J., Reese, J. C., Louis, J., Campbell, L. R., and Schapaugh, W. T. 2007. Feeding behavior by the soybean aphid (Hemiptera: Aphididae) on resistant and susceptible soybean genotypes. J. Econ. Entomol. 100:984-989.

Divol, F., Vilaine, F., Thibivilliers, S., Amselem, J., Palauqui, J.-C., Kusiak, C., and Dinant, S. 2005. Systemic response to aphid infestation by Myzus persicae in the phloem of Apium graveolens. Plant Mol. Biol. 57:517-540.

Efron, B., and Tibshirani, R. 2007. On testing the significance of sets of genes. Ann. Appl. Stat. 1:107-129.

El-Khawas, S. A. M., and El-Khawas, M. A. M. 2008. Interactions between Aphis gossypii (Glov.) and the common predators in eggplant and squash fields, with evaluating the physiological and biochemical aspects of biotic stress induced by two different aphid species, infesting squash and cabbage plants. Aust. J. Basic Appl. Sci. 2:183-193.

Ellis, C., Karafyllidis, L., and Turner, J. G. 2002. Constitutive activation of jasmonate signaling in an Arabidopsis mutant correlates with enhanced resistance to Erysiphe cichoracearum, Pseudomonas syringae, and Myzus persicae. Mol. Plant-Microbe Interact. 15:1025-1030.

Engelberth, J., Alborn, H. T., Schmelz, E. A., and Tumlinson, J. H. 2004 Airborne signals prime plants against insect herbivore attack. Proc. Natl. Acad. Sci. U.S.A. 101:1781-1785.

Falk, A., Feys, B. J., Frost, L. N., Jones, J. D. G., Daniels, M. J., and Parker, J. E. 1999. EDS1, an essential component of $R$ gene-mediated disease resistance in Arabidopsis has homology to eukaryotic lipases. Proc. Natl. Acad. Sci. U.S.A. 96:3292-3297.

Frost, C. J., Mescher, M. C., Carlson, J. E., and De Moraes, C. M. 2008. Plant defense priming against herbivores: Getting ready for a different battle. Plant Physiol. 146:818-824.

Gao, L.-L., Anderson, J. P., Klingler, J. P., Nair, R. M., Edwards, O. R., and Singh, K. B. 2007. Involvement of the octadecanoid pathway in bluegreen aphid resistance in Medicago truncatula. Mol. Plant-Microbe Interact. 20:82-93.

Gautier, L., Cope, L., Bolstad, B. M., and Irizarry, R. A. 2004. AffyAnalysis of Affymetrix GeneChip data at the probe level. Bioinformatics 20:307-315

Goggin, F. L., Shah, G., Williamson, V. M., and Ullman, D. E. 2004. Developmental regulation of Mi-mediated aphid resistance is independent of Mi-1.2 transcript levels. Mol. Plant-Microbe Interact. 17:532-536.

Grunewald, W., Karimi, M., Wieczorek, K., Van de Cappelle, E., Wischnitzki, E., Grundler, F., Inzé, D., Beeckman, T., and Gheysen, G. 2008. A role for AtWRKY23 in feeding site establishment of plantparasitic nematodes. Plant Physiol. 148:358-368.

Gutsche, A., Heng-Moss, T., Sarath, G., Twigg, P., Xia, Y., Lu, G., and Mornhinweg, D. 2009. Gene expression profiling of tolerant barley in response to Diuraphis noxia (Hemiptera: Aphididae) feeding. Bull. Entomol. Res. 99:163-173.

Han, Y., Wang, Y., Bi, J.-L., Yang, X.-Q., Huang, Y., Zhao, X., Hu, Y., and Cai, Q.-N. 2009. Constitutive and induced activities of defense-related enzymes in aphid-resistant and aphid-susceptible cultivars of wheat. J. Chem. Ecol. 35:176-182.

Hesler, L. S., and Dashiell, K. E. 2007. Resistance to Aphis glycines (Hemiptera: Aphididae) in various soybean lines under controlled laboratory conditions. J. Econ. Entomol. 100:1464-1469.

Hill, C. B., Li, Y., and Hartman, G. L. 2006a. A single dominant gene for resistance to the soybean aphid in the soybean cultivar Dowling. Crop Sci. 46:1601-1605.
Hill, C. B., Li, Y., and Hartman, G. L. 2006b. Soybean aphid resistance in soybean Jackson is controlled by a single dominant gene. Crop Sci. 46:1606-1608

Hill, C. B., Kim, K.-S., Crull, L., Diers, B. W., and Hartman, G. L. 2009. Inheritance of resistance to the soybean aphid in soybean PI 200538 Crop Sci. 49:1193-1200.

Hill, C. B., Crull, L., Herman, T. K., Voegtlin, D. J., and Hartman, G. L. 2010. A new soybean aphid (Hemiptera: Aphididae) biotype identified. J. Econ. Entomol. 103:509-515.

Hill, J. H., Alleman, R., Hogg, D. B., and Grau, C. R. 2001. First report of transmission of Soybean mosaic virus and Alfalfa mosaic virus by Aphis glycines in the New World. Plant Dis. 85:561-561.

Howe, G. A., and Jander, G. 2008. Plant immunity to insect herbivores. Annu. Rev. Plant Biol. 59:41-66.

Irizarry, R. A., Hobbs, B., Collin, F., Beazer-Barclay, Y. D., Antonellis, K. J., Scherf, U., and Speed, T. P. 2003. Exploration, normalization, and summaries of high density oligonucleotide array probe level data. Biostatistics 4:249-264.

Jiang, H., Li, H., Bu, Q., and Li, C. 2009. The RHA2a-interacting proteins ANAC019 and ANAC055 may play a dual role in regulating ABA response and jasmonate response. Plant Signal. Behav. 4:464-466.

Kaloshian, I., Lange, W. H., and Williamson, V. M. 1995. An aphidresistance locus is tightly linked to the nematode-resistance gene, $\mathrm{Mi}$, in tomato. Proc. Natl. Acad. Sci. U.S.A. 92:622-625.

Kang, S.-T., Rouf Mian, M. A., and Hammond, R. B. 2008. Soybean aphid resistance in PI 243540 is controlled by a single dominant gene. Crop Sci. 48:1744-1748.

Kanobe, C., McCarville, M. T., O’Neal, M., Tylka, G. L., and MacIntosh, G. C. Aphid infestations induce changes in fatty acid metabolism in soybean. Submitted.

Kempema, L. A., Cui, X., Holzer, F. M., and Walling, L. L. 2007. Arabidopsis transcriptome changes in response to phloem-feeding silverleaf whitefly nymphs. Similarities and distinctions in responses to aphids. Plant Physiol. 143:849-865.

Kim, J. C., Lee, S. H., Cheong, Y. H., Yoo, C.-M., Lee, S. I., Chun, H. J., Yun, D.-J., Hong, J. C., Lee, S. Y., Lim, C. O., and Cho, M. J. 2001. A novel cold-inducible zinc finger protein from soybean, SCOF-1, enhances cold tolerance in transgenic plants. Plant J. 25:247-259.

Kim, J. H., Kim, W. T., Kang, B. G., and Yang, S. F. 1997. Induction of 1-aminocyclopropane-1-carboxylate oxidase mRNA by ethylene in mung bean hypocotyls: Involvement of both protein phosphorylation and dephosphorylation in ethylene signaling. Plant J. 11:399-405

Kim, K.-S., Hill, C. B., Hartman, G. L., Mian, M. A. R., and Diers, B. W 2008. Discovery of soybean aphid biotypes. Crop Sci. 48:923-928.

Kim, K.-S., Bellendir, S., Hudson, K., Hill, C., Hartman, G., Hyten, D., Hudson, M., and Diers, B. 2010. Fine mapping the soybean aphid resistance gene Ragl in soybean. Theor. Appl. Genet. 120:1063-1071.

Kuśnierczyk, A., Winge, P. E. R., Jørstad, T. S., Troczyńska, J., Rossiter, J. T., and Bones, A. M. 2008. Towards global understanding of plant defence against aphids-Timing and dynamics of early Arabidopsis defence responses to cabbage aphid (Brevicoryne brassicae) attack. Plant Cell Environ. 31:1097-1115.

Lapitan, N. L. V., Li, Y. C., Peng, J. H., and Botha, A. M. 2007. Fractionated extracts of Russian wheat aphid eliciting defense responses in wheat. J. Econ. Entomol. 100:990-999.

Li, Q., Xie, Q.-G., Smith-Becker, J., Navarre, D. A., and Kaloshian, I. 2006. Mi-1-mediated aphid resistance involves salicylic acid and mitogen-activated protein kinase signaling cascades. Mol. Plant-Microbe Interact. 19:655-664.

Li, Y., Hill, C. B., and Hartman, G. L. 2004. Effect of three resistant soybean genotypes on the fecundity, mortality, and maturation of soybean aphid (Homoptera: Aphididae). J. Econ. Entomol. 97:1106-1111.

Li, Y., Zou, J., Li, M., Bilgin, D. D., Vodkin, L. O., Hartman, G. L., and Clough, S. J. 2008. Soybean defense responses to the soybean aphid. New Phytol. 179:185-195.

Libault, M., Wan, J. R., Czechowski, T., Udvardi, M., and Stacey, G. 2007. Identification of 118 Arabidopsis transcription factor and 30 ubiquitinligase genes responding to chitin, a plant-defense elicitor. Mol. PlantMicrobe Interact. 20:900-911.

Liu, H.-Y., Chiang, Y.-C., Pan, J., Chen, J., Salvadore, C., Audino, D. C Badarinarayana, V., Palaniswamy, V., Anderson, B., and Denis, C. L. 2001. Characterization of CAF4 and CAF16 reveals a functional connection between the CCR4-NOT complex and a subset of SRB proteins of the RNA polymerase II holoenzyme. J. Biol. Chem. 276:7541-7548.

Loake, G., and Grant, M. 2007. Salicylic acid in plant defence-the players and protagonists. Curr. Opin. Plant Biol. 10:466-472.

Lu, P.-L., Chen, N.-Z., An, R., Su, Z., Qi, B.-S., Ren, F., Chen, J., and Wang, X.-C. 2007. A novel drought-inducible gene, ATAF1, encodes a NAC family protein that negatively regulates the expression of stressresponsive genes in Arabidopsis. Plant Mol. Biol. 63:289-305. 
Ma, R., Chen, J. L., Cheng, D. F., and Sun, J. R. 2010. Activation of defense mechanism in wheat by polyphenol oxidase from aphid saliva. J. Agric. Food Chem. 58:2410-2418.

Mantelin, S., Bhattarai, K. K., and Kaloshian, I. 2009. Ethylene contributes to potato aphid susceptibility in a compatible tomato host. New Phytol. 183:444-456.

Martinez de Ilarduya, O., Xie, Q., and Kaloshian, I. 2003. Aphid-induced defense responses in $M i$ - 1 -mediated compatible and incompatible tomato interactions. Mol. Plant-Microbe Interact. 16:699-708.

Mazarei, M., Elling, A. A., Maier, T. R., Puthoff, D. P., and Baum, T. J. 2007. GmEREBP1 is a transcription factor activating defense genes in soybean and Arabidopsis. Mol. Plant-Microbe Interact. 20:107-119.

McCarville, M. T., O’Neal, M., Tylka, G. L., Kanobe, C., and MacIntosh, G. C. 2012. A nematode, fungus, and aphid interact via a shared host plant: Implications for soybean management. Entomol. Exp. Appl. 143:55-66.

McCornack, B. P., Ragsdale, D. W., and Venette, R. C. 2004. Demography of soybean aphid (Homoptera : Aphididae) at summer temperatures. J. Econ. Entomol. 97:854-861.

Mensah, C., DiFonzo, C., Nelson, R. L., and Wang, D. 2005. Resistance to soybean aphid in early maturing soybean germplasm. Crop Sci. 45:2228-2233.

Mensah, C., DiFonzo, C., and Wang, D. 2008. Inheritance of soybean aphid resistance in PI 567541B and PI 567598B. Crop Sci. 48:17591763.

Mewis, I., Appel, H. M., Hom, A., Raina, R., and Schultz, J. C. 2005. Major signaling pathways modulate Arabidopsis glucosinolate accumulation and response to both phloem-feeding and chewing insects. Plant Physiol. 138:1149-1162.

Mian, M. A. R., Kang, S.-T., Beil, S., and Hammond, R. 2008. Genetic linkage mapping of the soybean aphid resistance gene in PI 243540. Theor. Appl. Genet. 117:955-962.

Midland, S. L., Keen, N. T., Sims, J. J., Midland, M. M., Stayton, M. M., Burton, V., Smith, M. J., Mazzola, E. P., Graham, K. J., and Clardy, J. 1993. The structures of syringolides 1 and 2, novel C-glycosidic elicitors from Pseudomonas syringae pv. tomato. J. Org. Chem. 58:2940-2945.

Milligan, S. B., Bodeau, J., Yaghoobi, J., Kaloshian, I., Zabel, P., and Williamson, V. M. 1998. The root knot nematode resistance gene $M i$ from tomato is a member of the leucine zipper, nucleotide binding, leucine-rich repeat family of plant genes. Plant Cell 10:1307-1320.

Nombela, G., Williamson, V. M., and Muñiz, M. 2003. The root-knot nematode resistance gene $\mathrm{Mi}-1.2$ of tomato is responsible for resistance against the Whitefly Bemisia tabaci. Mol. Plant-Microbe Interact. 16:645-649.

Olsen, A. N., Ernst, H. A., Leggio, L. L., and Skriver, K. 2005. NAC transcription factors: Structurally distinct, functionally diverse. Trends Plant Sci. 10:79-87

Pandey, S. P., and Baldwin, I. T. 2007. RNA-directed RNA polymerase 1 (RdR1) mediates the resistance of Nicotiana attenuata to herbivore attack in nature. Plant J. 50:40-53.

Pandey, S. P., Shahi, P., Gase, K., and Baldwin, I. T. 2008. Herbivoryinduced changes in the small-RNA transcriptome and phytohormone signaling in Nicotiana attenuata. Proc. Natl. Acad. Sci. U.S.A. 105:4559-4564

Pareja, M., Mohib, A., Birkett, M. A., Dufour, S., and Glinwood, R. T. 2009. Multivariate statistics coupled to generalized linear models reveal complex use of chemical cues by a parasitoid. Anim. Behav. 77:901909.

Pfaffl, M. W. 2001. A new mathematical model for relative quantification in real-time RT-PCR. Nucleic Acids Res. 29:e45

Ragsdale, D. W., Landis, D. A., Brodeur, J., Heimpel, G. E., and Desneux, N. 2011. Ecology and management of the soybean aphid in North America. Annu. Rev. Entomol. 56:375-399.

Rossi, M., Goggin, F. L., Milligan, S. B., Kaloshian, I., Ullman, D. E., and Williamson, V. M. 1998. The nematode resistance gene $M i$ of tomato confers resistance against the potato aphid. Proc. Natl. Acad. Sci. U.S.A. 95:9750-9754.

Rousseeuw, P. J. 1987. Silhouettes: A graphical aid to the interpretation and validation of cluster analysis. J. Comput. Appl. Math. 20:53-65.

Rushton, P. J., Somssich, I. E., Ringler, P., and Shen, Q. J. 2010. WRKY transcription factors. Trends Plant Sci. 15:247-258.

Sarowar, S., Oh, H. W., Cho, H. S., Baek, K.-H., Seong, E. S., Joung, Y. H., Choi, G. J., Lee, S., and Choi, D. 2007. Capsicum annuum CCR4associated factor $C a C A F 1$ is necessary for plant development and defence response. Plant J. 51:792-802.
Schmutz, J., Cannon, S. B., Schlueter, J., Ma, J., Mitros, T., Nelson, W., Hyten, D. L., Song, Q., Thelen, J. J., Cheng, J., Xu, D., Hellsten, U., May, G. D., Yu, Y., Sakurai, T., Umezawa, T., Bhattacharyya, M. K., Sandhu, D., Valliyodan, B., Lindquist, E., Peto, M., Grant, D., Shu, S., Goodstein, D., Barry, K., Futrell-Griggs, M., Abernathy, B., Du, J., Tian, Z., Zhu, L., Gill, N., Joshi, T., Libault, M., Sethuraman, A. Zhang, X.-C., Shinozaki, K., Nguyen, H. T., Wing, R. A., Cregan, P., Specht, J., Grimwood, J., Rokhsar, D., Stacey, G., Shoemaker, R. C., and Jackson, S. A. 2010. Genome sequence of the palaeopolyploid soybean. Nature 463:178-183.

Smyth, G. K. 2004. Linear models and empirical Bayes methods for assessing differential expression in microarray experiments. Stat. Appl Genet. Mol. Biol. 3:Article3. Published online

Staswick, P. E., and Tiryaki, I. 2004. The oxylipin signal jasmonic acid is activated by an enzyme that conjugates it to isoleucine in Arabidopsis. Plant Cell 16:2117-2127.

Storey, J. D., Taylor, J. E., and Siegmund, D. 2004. Strong control, conservative point estimation and simultaneous conservative consistency of false discovery rates: A unified approach. J. R. Stat. Soc. B 66:187-205.

Studham, M. E., and MacIntosh, G. C. 2012. Phytohormone signaling pathway analysis method for comparing hormone responses in plantpest interactions. BMC Res. Notes 5:392.

Studham, M., MacIntosh, G. C., Avendaño, F., Soh, D., and Tylka, G. L. 2009. The soybean resistance gene Ragl does not protect against soybean cyst and root-knot nematodes. Plant Health Progress PHP-20090401-2001-BR.

Tao, Y., Xie, Z., Chen, W., Glazebrook, J., Chang, H.-S., Han, B., Zhu, T., Zou, G., and Katagiri, F. 2003. Quantitative nature of Arabidopsis responses during compatible and incompatible interactions with the bacterial pathogen Pseudomonas syringae. Plant Cell 15:317-330.

Uppalapati, S. R., Ishiga, Y., Wangdi, T., Kunkel, B. N., Anand, A., Mysore, K. S., and Bender, C. L. 2007. The phytotoxin coronatine contributes to pathogen fitness and is required for suppression of salicylic acid accumulation in tomato inoculated with Pseudomonas syringae pv. tomato DC3000. Mol. Plant-Microbe Interact. 20:955-965.

van de Mortel, M., Recknor, J. C., Graham, M. A., Nettleton, D., Dittman, J. D., Nelson, R. T., Godoy, C. V., Abdelnoor, R. V., Almeida, Á. M. R., Baum, T. J., and Whitham, S. A. 2007. Distinct biphasic mRNA changes in response to Asian soybean rust infection. Mol. PlantMicrobe Interact. 20:887-899.

Vaucheret, H., Béclin, C., and Fagard, M. 2001. Post-transcriptional gene silencing in plants. J. Cell Sci. 114:3083-3091.

Walling, L. L. 2008. Avoiding effective defenses: Strategies employed by phloem-feeding insects. Plant Physiol. 146:859-866.

Walz, C., Giavalisco, P., Schad, M., Juenger, M., Klose, J., and Kehr, J. 2004. Proteomics of curcurbit phloem exudate reveals a network of defence proteins. Phytochemistry 65:1795-1804.

Weingart, H., Ullrich, H., Geider, K., and Völksch, B. 2001. The role of ethylene production in virulence of Pseudomonas syringae pvs. glycinea and phaseolicola. Phytopathology 91:511-518.

Will, T., and van Bel, A. J. E. 2006. Physical and chemical interactions between aphids and plants. J. Exp. Bot. 57:729-737.

Wu, Z., Irizarry, R. A., Gentleman, R., Martinez-Murillo, F., and Spencer, F. 2004. A model-based background adjustment for oligonucleotide expression arrays. J. Am. Stat. Assoc. 99:909-917.

Zarate, S. I., Kempema, L. A., and Walling, L. L. 2007. Silverleaf whitefly induces salicylic acid defenses and suppresses effectual jasmonic acid defenses. Plant Physiol. 143:866-875.

Zhang, G., Gu, C., and Wang, D. 2010. A novel locus for soybean aphid resistance. Theor. Appl. Genet. 120:1183-1191.

Zhu, J., and Park, K.-C. 2005. Methyl salicylate, a soybean aphid-induced plant volatile attractive to the predator Coccinella septempunctata. J. Chem. Ecol. 31:1733-1746.

Zou, J., Rodriguez-Zas, S., Aldea, M., Li, M., Zhu, J., Gonzalez, D. O., Vodkin, L. O., DeLucia, E., and Clough, S. J. 2005. Expression profiling soybean response to Pseudomonas syringae reveals new defenserelated genes and rapid HR-specific downregulation of photosynthesis. Mol. Plant-Microbe Interact. 18:1161-1174.

\section{AUTHOR-RECOMMENDED INTERNET RESOURCES}

Bioconductor open source software website: www.bioconductor.org

Soybase website: www.soybase.org

Soybean Breeder's Toolbox SoyChip Annotations: www.soybase.org/AffyChip 